\title{
The Last Glacial Maximum Human Burial from Liang Lemdubu in Northern Sahulland
}

\author{
David Bulbeck \\ School of Archaeology and Anthropology, The Australian National University, Canberra, ACT, Australia
}

\section{Introduction}

The one metre square test pit (Test Pit C) excavated by O'Connor, Spriggs and Veth at the Liang Lemdubu site, Aru, recovered a semi-complete human skeleton. When alive, the individual ('Lemdubu Woman') had been a tall woman of around $166 \mathrm{~cm}$ in height, with a rugged skull and quite large teeth by female standards (Fig. 12.1). Age at death is estimated at around 30 years old based on the morphology of the pubic symphysis and stage of tooth wear. The vertebral discs, right tibia and right clavicle present a series of holes which are suggestive of metastatic lesions. All parts of the skeleton are definitely represented except the fingers and toes. The bulk of the material was recovered within the cramped depth of $30 \mathrm{~cm}$ between Spits 18 and 23, and the remains include tilted and vertically inverted elements. These observations are incompatible with a standard primary burial and, in the most likely scenario, the corpse had decomposed to a state of bones and connective tissue which had then been buried in bundles.

As discussed in Chapter 9 (this volume), the age of the burial would be placed at around $16,000-18,000$ years ago based on its stratigraphic context and ESR dating of its tooth from Spit 19, but we also have a conflicting, middle Holocene chronometric determination on the bone. Although for the reasons outlined in Chapter 9 the bone date has been dismissed as unreliable, it was thought that for the sake of completeness Lemdubu Woman should be compared with both Pleistocene and Holocene aged skeletal materials.

The two very different estimates of the skeleton's age would imply either a similarity with terminal Pleistocene Australian female specimens, such as those from Coobool Creek in southeast Australia, or an affinity with middle Holocene Nusatenggara female specimens such as Leang Toge (see Fig. 12.2). Few morphological comparisons support the latter alternative and, instead, a diagnostic likeness clearly emerges with ancient Australians. The Lemdubu burial should therefore be considered representative of the Last Glacial Maximum inhabitants of the northwestern rim of the 


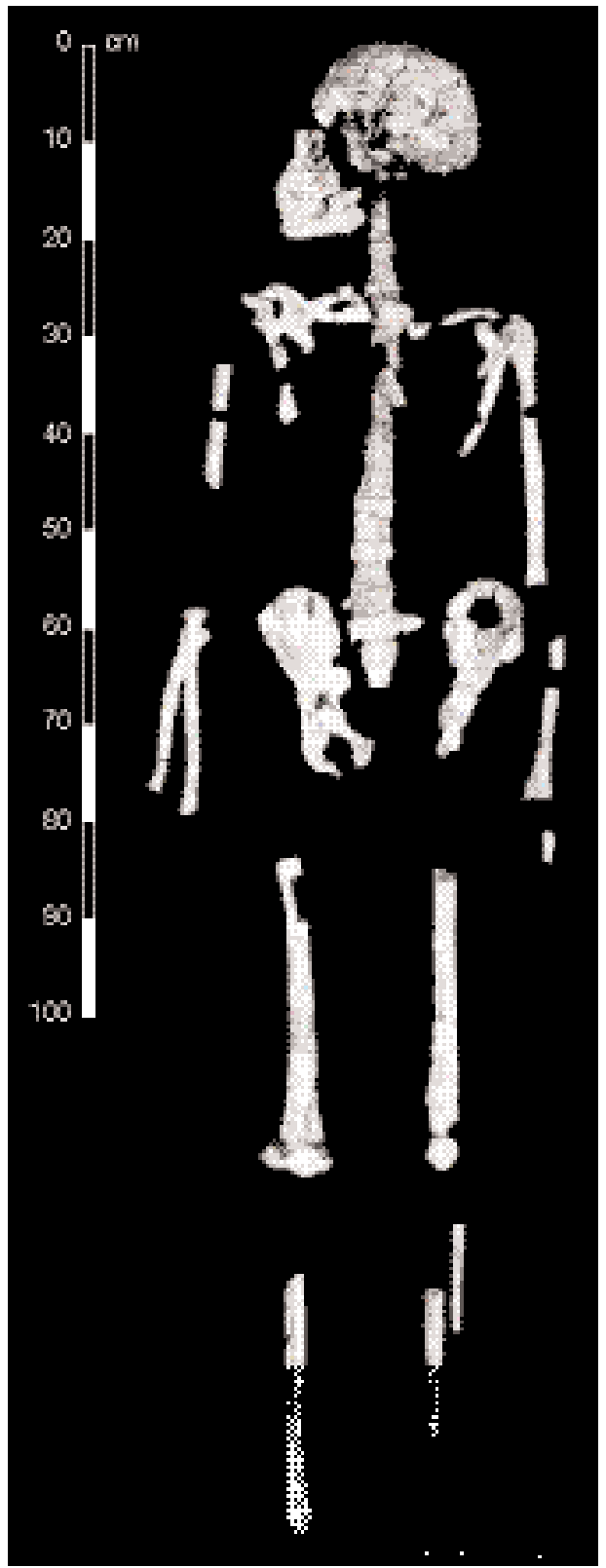

Figure 12.1 Liang Lemdubu: reconstruction of the semi-complete skeleton

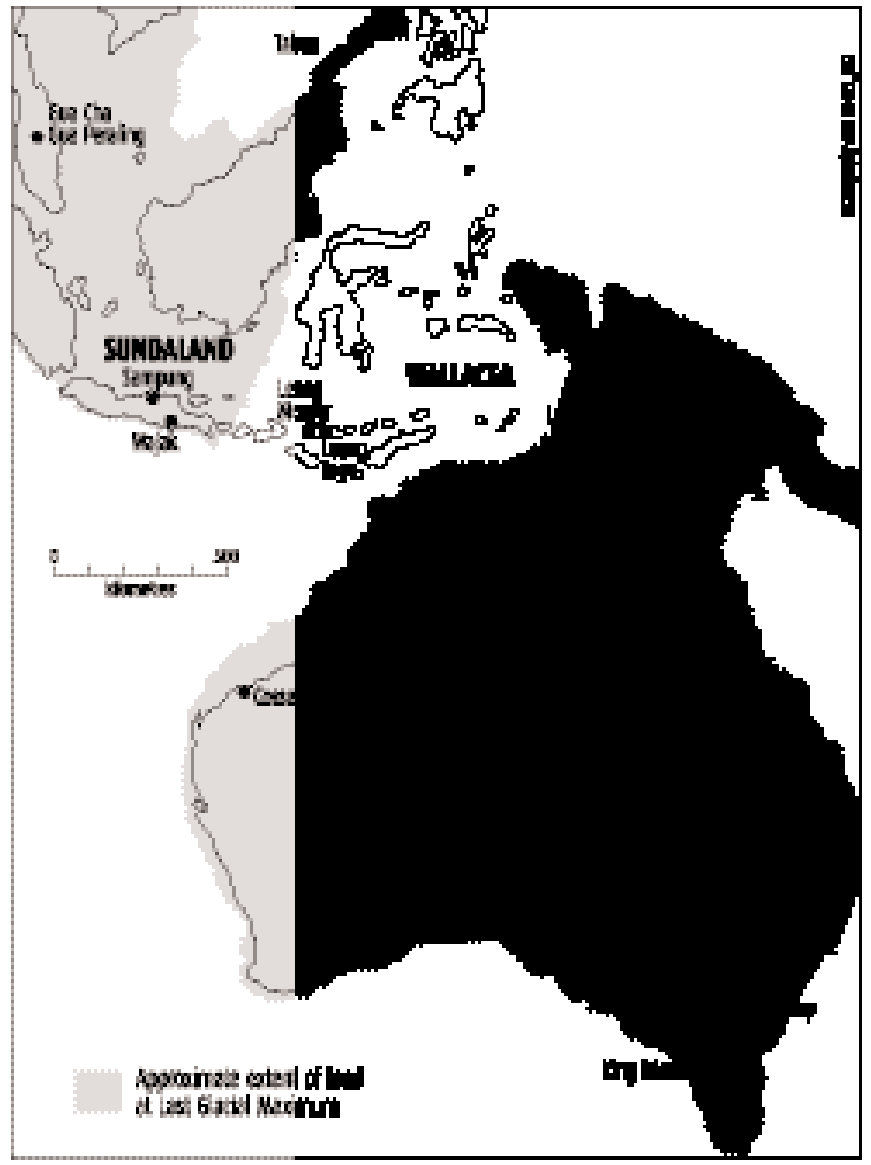

Figure 12.2 Map indicating fossil sites mentioned in the text (Lambert Azimuthal Equal-Area Projection)

vast, former continent of Sahulland. While there certainly are differences with penecontemporary southeastern Sahulland burials, these may be attributed to chronological and/or geographical variation.

\section{Treatment and Disposition of the Material}

The author received approximately 400 fragments of suspected human material in over 50 plastic bags whose contents ranged from a single fragment to associations that weighed over 500g (Table 12.1). Most had been identified as human bone during the excavation, supplemented with further fragments when Ken Aplin separated the faunal and the human material. A small number of fragments proved not to be human, and a similar number are human but evidently do not belong to Lemdubu Woman. Because none of the material had been cleaned, the author undertook this labour by brushing off the loose adhering sediments, and employing fine, stainless-steel instruments (as used 
Table 12.1 Liang Lemdubu: distribution of human material from the excavation

\begin{tabular}{|c|c|c|c|}
\hline SPIT & WEIGHT $(g)$ & NO. FRAGS & CONTENTS \\
\hline 1 & 0.5 & 2 & Distal pedal phalanx, tooth enamel fragment* \\
\hline 6 & 0.1 & 1 & Molar fragment" \\
\hline 7 & 4.7 & 2 & Sphenoid body, right lunate* \\
\hline 10 & 0.8 & 1 & Proximal manual phalanx* \\
\hline 11 & 0.3 & 1 & Left second distal pedal phalanx \\
\hline 12 & 2.1 & 2 & Femur", calcaneus \\
\hline 14 & 0.5 & 1 & Femur: \\
\hline 15 & 1.3 & 1 & Basicranium \\
\hline 16 & 0.5 & 1 & Right lower first incisor \\
\hline 17 & 15.9 & 2 & Right femur epicondyle \\
\hline 18 & 188.9 & 29 & Right femur, right tibia, right humerus, left ulna, calvarial fragments \\
\hline 19 & 946.7 & 80 & $\begin{array}{l}\text { Left humerus, left radius, right ulna, calvarium, face, mandible, teeth, cervical \& upper thoracic } \\
\text { vertebrae, right lunate, rib \& scapula fragments\# }\end{array}$ \\
\hline 20 & 450.0 & 79 & $\begin{array}{l}\text { Right femur, right tibia, left femur, left tibia, right fibula, calvarial fragments, right upper third } \\
\text { molar, cervical \& thoracic vertebrae, lower lumbar \& upper sacral vertebrae, rib \& scapula } \\
\text { fragments, right \& left pelvic iliac fragments, metacarpal fragment }\end{array}$ \\
\hline 21 & 451.3 & 142 & $\begin{array}{l}\text { Right tibia, right humerus, left ulna, left humerus, right ulna, left femur, right radius, left fibula, } \\
2 \text { teeth, calvarial frags, lower thoracic \& upper lumbar vertebrae, ribs, right \& left scapulae, } \\
\text { right \& left partial clavicles, sternum frag, right pelvic iliac fragments }\end{array}$ \\
\hline 22 & 285.0 & 39 & $\begin{array}{l}\text { Right tibia, left femur, left humerus, right radius, left fibula, right l I, rib \& sacral fragments, } \\
\text { right \& left clavicle frags, sternum frags, right \& left pelvic iliac \& pubic fragments, right talus }\end{array}$ \\
\hline 23 & 97.3 & 11 & $\begin{array}{l}\text { Right \& left patellae, right pelvic iliac, ischial \& pubic fragments, left pelvic ischial \& pubic } \\
\text { fragments, right talus }\end{array}$ \\
\hline 25 & 1.1 & 1 & Rib fragment+ + \\
\hline TOTAL & 2447.0 & 394 & \\
\hline
\end{tabular}

NB: "well-burnt and light in weight; unburnt but not clearly Lemdubu Woman; \#the remains further include one forearm and two humerus fragments, all burnt, evidently not Lemdubu Woman $(47.3 \mathrm{~g}) ;+$ only possibly human

in anatomical sectioning) to remove the thin calcreted skin which coated most of the fragments. Great care was taken to reveal the underlying surface morphology without damage to the original bone. Washing and chemical methods of cleaning were avoided to ensure there would be no ionic contamination of the fossilized tissue. During the cleaning, five samples of the loose adhering sediment (in the bags marked 200, 234, 235, 236, and 248) were collected and stored in plastic bags. These were passed onto Matthew Spriggs in June 2000 to assist Rainer Grün's efforts in dating the skeleton through Electron Spin Resonance.

The osteological material is at an advanced stage of semi-fossilization and its condition appears no different from that of the faunal fragments seen by the author. None of the fragments assignable to Lemdubu Woman show signs of heat exposure. However, the distal diaphysis of her right humerus exhibited four parallel, horizontal cutmarks on its dorsal face and three angled parallel cutmarks on its ventral face, while a deep, sharp cutmark was observed on the proximal fragment of her right ulna. These incisions could suggest that some dismemberment of the corpse had been necessary to help cram the remains into the bounds of the grave cavity. Three cutmarks were also noted posterior to the acetabulum of one of the pelves, but the incisions appeared fresh and could be damage from the excavators' trowels.

After cleaning, the fragments were weighed, identified to their skeletal element, and glued with Tarzan's Grip ${ }^{\mathrm{TM}}$ as far as possible into complete elements. Red modelling plasticene was sometimes used to simulate missing portions of bone and to hold fragments together along unstable joins. Information on the excavated context of the fragments was recorded in notes and laboratory sketches of the reconstructed elements during reconstruction. I concurrently recorded 
metrical and morphological features which are more easily observed on fragments than on complete or re-assembled specimens (thickness of the cranial bone, its diploe and inner and outer tables; morphology and thicknesses of the medullary cavity and the cortical walls of the limb bone shafts; and so forth). These measurements, and other small-scale measurements like tooth diameters, were made with a Mitutoyo electronic calliper accurate to $0.01 \mathrm{~mm}$. The remainder of my measurements were performed with a GPM spreading calliper, Stalon sliding calliper, Stalon coordinate calliper, GPM protractor (angulometer), and the ANU Biological Anthropology Laboratory's mandible board, according to the specifications in the measurement definitions sourced in due course below.

Following reconstruction and photography, Lemdubu Woman was repatriated to the National Research Centre of Archaeology, Jakarta, in late 2000. This photographed and remitted material (Fig. 12.1) excludes a residue of the extremity and other fragments which were finally identified as human in 2001 and passed onto the author. Further, prior to remittance, three samples were extracted from the skeleton and sacrificed to assist in dating it. One of these specimens is the lower left third molar, which had been retrieved as a loose tooth from Spit 19. In addition, a section was cut from the medial diaphysis fragment of the right femur (retrieved from Spit 18) for the purposes of the AMS date from AINSE, and Donald Pate's attempted stable isotope ratio assay. Another sample of femoral bone was later submitted to the AMS dating facilities at Oxford as a check on the AINSE determination.

The distribution of the human material is detailed in Table 12.1. Ninety-nine per cent of the remains, by weight, was recorded between Spits 18 and 22. Within this band, the elements' distribution is not random, and roughly proceeds from the skull and limb bones higher up, to the vertebrae, ribs and scapulae, then the clavicles, pelves and sternum, and the patellae at the bottom. Hand and foot bones are scarce, and comprise merely a single right carpal (the lunate) and

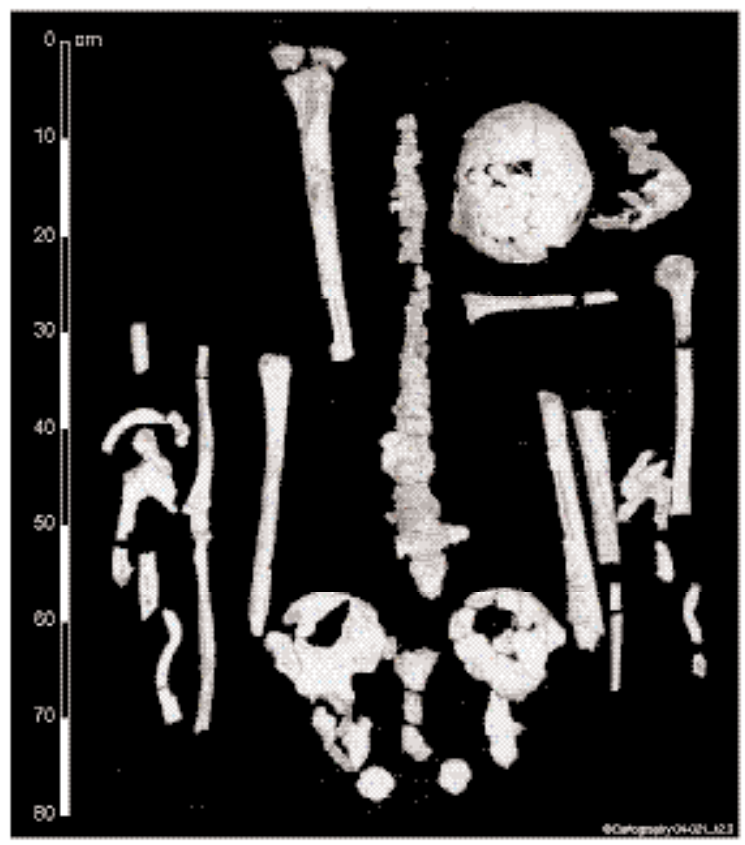

Figure 12.3 Liang Lemdubu: approximate distribution of the elements of Lemdubu Woman in the test pit, with the vertical scale exaggerated about 2.5 times, and elements represented in vertical orientation metacarpal fragment identified at an intermediate level, and three right talus fragments observed among the most deeply buried remains. The recorded depths of fragments from the same skeletal element indicate that the left femur, left humerus, right radius, left ulna, pelves and most of the vertebral column had been oriented or, more probably, slanted right way up at the time of excavation, whereas the right femur, right tibia and right ulna had sat (or been tilted) upside down. The uppermost skull fragments belong to the left calotte; slightly beneath them were the superior calotte fragments, face and jaws; and the deepest fragments pertain to the right posterior calvarium - as though the skull had leaned behind the right shoulder at the time of burial. The vertebral discs from the fourth lumbar to the second sacral vertebral positions were recovered as a single block cemented together at the discs (Fig. 12.3).

Moreover, $65 \%$ of the human material by weight came from Spits 18 to 20 where the excavators noted a boulder which partly covered the burial, but with the bone fragments often protruding along the sides of the boulder. Only 
the right radius, left fibula, clavicles, sternum, and patellae completely underlay the boulder (see Table 12.1). It seems likely that the boulder had originally been placed to cover the burial, but sank into the deposits and displaced many of the fragments upwards. Further upward movement of the right lower first incisor (which clearly belongs to Lemdubu Woman) to Spit 16, and three basicranial and extremity fragments (which may belong to the burial) to Spits 11 to 15 , could have occurred through subsequent scuffage. These observations permit three possible scenarios.

Lemdubu Woman could have been a primary burial seated in a tightly curled hocker position after the hands and feet (except the parts closest to the articulation with the limbs) had been removed. At a later stage, following decomposition of the corpse, the mourners could have exposed the skeleton, handled three of the limb bones, and then replaced them upside down, at the same time disturbing other bones. Perhaps the burial had been covered by loose grave fill as the corpse decomposed, and the boulder was placed to seal the grave after the bones had been handled. Alternatively, the boulder could have covered the corpse while it decomposed, and then been re-positioned at final burial. Raath's $(1996: 17,87)$ study of ethnographic burial practices among Western Australian Aborigines would account for this scenario in terms of incapacitating the deceased through wreaking intentional damage to the manual extremities, followed by the 'inquest' when the grave is re-opened, and the defleshed bones are inspected to identify the culprits responsible for the death. Raath (1996:100) further noted instances where the corpse had been jumped or stood upon to make it fit into a grave no more than two feet $(65 \mathrm{~cm})$ deep, and a practice like this could account for the compression of a primary burial into the restricted space where most of the bones belonging to Lemdubu Woman were found.

Two further scenarios may be entertained, and in both of them the boulder would have been placed on top of the burial at the end of the mortuary ceremony. In the second possible scenario, the hands and legs might have been severed from the corpse, the feet from the legs, and the left leg or both legs separated into thigh and calf. The intentions could have been to disable the deceased and/or fit the body parts into a restricted cavity (cf. Raath 1996:100). The torso with its attached skull and arms would have been thrust into the grave, and the legs fitted in with the knee joints at the bottom, either with the thigh and calf as separate parts (applicable at least to the left leg), or tightly flexed with the knee oriented downwards (possibly applicable to the right leg).

In the third scenario, which is the most parsimonious and plausible, the corpse had been largely defleshed through exposure to the elements (cf. Raath 1996:120-3) or preliminary burial, but still partly held together by ligaments when the act of secondary burial occurred. The mourners would have overlooked most of the hands and feet when they collected the body parts for secondary burial, then redeposited the remainder of the corpse in bundles similar to those suggested for the second scenario. The approximately upright orientation of most of Lemdubu Woman's skeleton could have resulted from residual preservation of some connective tissue at the time of secondary burial, or the detail of the mortuary procedure.

The minuscule assemblage of human remains that are burnt (Table 12.1) represent the deposition of human scraps unrelated to the main burial event. We may infer this because the tooth fragments and lunate in the upper spits, and the burnt arm bone fragments found in Spit 19, duplicate osteological elements that are unambiguously attributed to Lemdubu Woman. The Spit 19 fragments mentioned here may have been deposited as part of the grave fill, or may have lain at the same level with the burial in a different part of the test pit. However, the burnt fragments from the upper spits must have postdated the burial.

The unburnt pedal bone from Spits 11 and 12, and the Spit 15 basicranial fragment, may or may not relate to Lemdubu Woman. Their unburnt status is not diagnostic of their mode of deposition because post-depositional processes (e.g. incorporation in the walls of a hearth scooped into the deposits) are responsible for most cases of burnt archaeological bone. These fragments are compatible with all three burial scenarios. They could have dropped onto the shelter floor during a 
secondary burial, or, if a manipulated primary burial had occurred, the pedal bones might have been detached during dismemberment of the corpse's extremities. While it could be argued that these three unburnt fragments would allow for the grave to have been cut from a level as high as Spit 11, the burial would still be marginally Pleistocene because, as noted elsewhere in this volume, the Pleistocene-Holocene boundary is placed at around Spit 10. Further to the point, they could have derived from Lemdubu Woman and still not rule out cutting of the grave from much lower in the deposits, e.g. Spit 17 where the human remains begin in earnest (Table 12.1). This is because, if they had been detached from the main skeleton at the time of burial, they could have been scuffed upwards as further deposits accumulated, or been moved upwards through localized disturbance such as construction of a hearth. Thus the human scraps in the higher spits do not constitute evidence against the burial of Lemdubu Woman from Spit 17 (dated to about 17,000 radiocarbon years ago), because none of them need relate to that individual and, even if any do, they would have been susceptible to upward post-depositional disturbance.

In summary, the mortuary ceremony for Lemdubu Woman most probably occurred at around 17,000 radiocarbon years ago. It was neither a simple primary burial nor the secondary disposal of completely disarticulated bones and fragments, but lay somewhere in between. The cutmarks observed on the right humerus and ulna provide direct evidence for the scenario which invokes dismemberment of the corpse, but similar cutmarks could also have been effected at some point in either of the other two possibilities, the inquest and secondary burial scenarios. Whatever the precise detail, the burial displays similarities with ethnographic practices recorded among Western Australian Aborigines (Raath 1996:139-42).

\section{Sex and Age Assessment}

The adult status of the burial is clear from the fully fused status of all of the extant epiphyses, the fused basilar synchondrosis, and the occluded status of all teeth including the third molars. The morphology of the pelvis (Fig. 12.4) demonstrates the specimen's female status (cf. Brothwell 1981:62-3). The right, greater sciatic notch is very wide, measuring $87^{\circ}$, high within the female

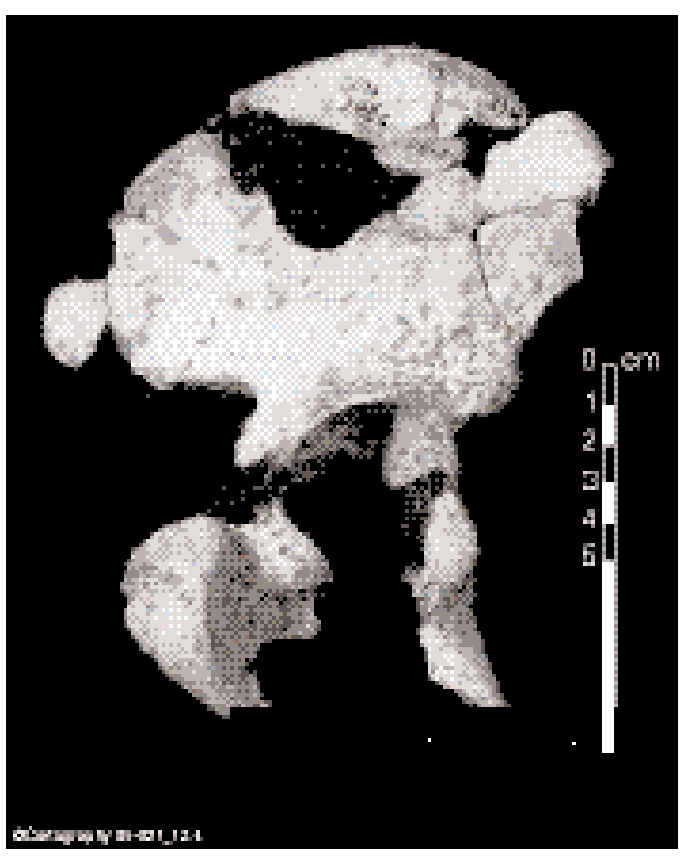

Figure 12.4 Liang Lemdubu: the Lemdubu Woman right innominate range found among humans generally $\left(\sim 60-95^{\circ}\right)$, and above the male range $\left(\sim 30-65^{\circ}\right)$. The left side (but not the right) shows a well-developed preauricular sulcus, another female marker. In relation to the sexually dimorphic, innominate measurements recorded on Australian Aborigines (Davivongs 1963a), the Lemdubu values compare well with those of female Australians (Table 12.2). Only on ischial length and coxal index are the Lemdubu values masculine trending, though still within the female range. Elsewhere, Lemdubu falls outside the male range on three indicators, and barely scrapes in the male range on several others (the female status of the Leang Toge innominates, included in Table 12.2 for comparative purposes, is even clearer than is the case with Lemdubu Woman). The gracile status of Lemdubu Woman's clavicles, especially the height at the mid-point (eight millimetres right, $7.5 \mathrm{~mm}$ left) which falls below the male Aboriginal range, and is low 
within the female range (Ray 1959:219), further indicates a female status. Most other observations on the postcranial skeleton are consistent with this assessment.

If the skull alone had been present it would certainly have been (mis-) classified as male (Table 12.3). Lemdubu Woman scores at least 15 on the seven sex discrimination traits of Larnach and Freedman (1964), and 14 in Brown's (1989:19-20) revised system, and so would lie in the male range as has been determined for both recent Australian Aborigines and for the markedly rugged, terminal Pleistocene crania from Coobool Creek in the Murray Valley (Brown 1989:19-25). However, it need not follow that Lemdubu Woman's population was morphologically more rugged than the population to which Coobool Creek belonged, as she may represent the zone of male-female overlap that is to be expected in any population.

Lemdubu Woman had evidently died before reaching middle age. Some closure of the ectocranial aspect of the coronal, sagittal and lambdoid sutures would usually be expected by the thirties (Szilvássy 1988:430), but there is no sign of this on the Lemdubu skull. The first, second and third lower molars all show tooth wear that closely matches the average expression for AngloSaxon individuals of about 25 years of age; as the gradient of tooth wear closely matches this Anglo-Saxon standard, the rate of occlusal wear must have been similar to the Anglo-Saxon average and, accordingly, Lemdubu Woman could not have died at an age very different from 25 (Miles 1963). However, the morphology of the pubic symphysis suggests an older individual. A ventral rampart can be observed in an active stage of formation on both the left and right faces,

Table 12.2 Liang Lemdubu and Leang Toge innominate measurements compared to Australians

\begin{tabular}{|c|c|c|c|c|}
\hline MEASUREMENT & LEMDUBU & L. TOGE & AUSTRALIAN FEMALE MEAN & AUSTRALIAN MALE RANGE \\
\hline Maximum innominate length & $188(\mathrm{R}), \geq 190(\mathrm{~L})$ & $180(\mathrm{~L})$ & $182.0 \pm 7.3$ & $178-221$ \\
\hline Iliac breadth & $\geq 139$ (R) & $143(\mathrm{~L})$ & $142.2 \pm 7.2$ & $133-167$ \\
\hline Coxal Index & $\geq 73.9$ (R) & $79.4(\mathrm{~L})$ & $78.0 \pm 2.8$ & $70.1-80.9$ \\
\hline Length of pubic symphysis & $32(\mathrm{R}), 33(\mathrm{~L})$ & - & $34.5 \pm 3.1$ & $27-44$ \\
\hline Acetabulum vertical diameter" & $44(\mathrm{R}, \mathrm{L})$ & $43(\mathrm{R})$ & $45.9 \pm 2.0$ & $45-58$ \\
\hline Acetabulum horizontal diameter & $46.5(R)$ & $43(\mathrm{~L})$ & $45.5 \pm 1.9$ & $45-57$ \\
\hline Pubic length: & $74(\mathrm{R})$ & - & $69.2 \pm 5.1$ & $54-73$ \\
\hline Ischial length & $82(\mathrm{R})$ & - & $74.7 \pm 3.6$ & $74-91$ \\
\hline Ischium-pubis index" & $90.2(\mathrm{R})$ & - & $92.7 \pm 6.0$ & $70.9-86.8$ \\
\hline Greater sciatic notch greatest width & $\leq 52(\mathrm{R})$ & $47(\mathrm{~L})$ & $50.9 \pm 3.8$ & $37-55$ \\
\hline Greater sciatic notch greatest depth & $\sim 23(\mathrm{R})$ & $17(\mathrm{~L})$ & $26.1 \pm 2.7$ & $18-31$ \\
\hline Greater sciatic notch index & $\sim 44.2$ (R) & $36.2(\mathrm{~L})$ & $51.4 \pm 5.5$ & $37.5-77.5$ \\
\hline
\end{tabular}

NB: measurements in mm; (R) indicates right side, and (L) indicates left side. Australian data from Davivongs (1963a), where the measurements are also defined. Leang Toge measurements from Jacob (1967:87). Lemdubu measurements fall outside the Australian male range on the asterisked measurements and index

Table 12.3 Liang Lemdubu: sex assessment of the skull by Australian standards

\begin{tabular}{lrrr}
\hline TRAIT & EXPRESSION & $\begin{array}{c}\text { BROWN'S (1989:19-20) } \\
\text { SCORE }\end{array}$ & $\begin{array}{c}\text { LARNACH AND FREEDMAN'S } \\
\text { (1964) SCORE }\end{array}$ \\
\hline Glabella development & Martin 5 & 3 & 3 \\
Superciliary ridges & Medium & 2 & 2 \\
Zygomatic trigone & Medium & 2 & 2 \\
(Right) malar tuberosity & Slight & 1 & 1 \\
(Left) mastoid process size & 122 (very large) & 3 & 3 \\
Palate size module & 41.4 & 2 & 3 \\
Nuchal musculature & Not extant & $1-3$ & $1-3$ \\
All seven traits & & $14-16$ & $15-17$ \\
\hline
\end{tabular}

NB: see section on cranial morphology below for further background 
flanked by a largely planed surface on both sides of the rampart on the left pubis, and a slightly more billowed surface on the right pubis. These features correspond to median ages in the 30s, and age ranges whose minimum value often exceeds 27 or 28 years old, for Components I to III as identified by Gilbert and McKern (1973) for female pubic bones (Table 12.4). Further, in terms of the Suchey-Brooks scheme for female pubic age determination, both of Lemdubu Woman's surfaces would correspond to phase IV, whose mean age is 38.2 and $95 \%$ range is 26-70 years old (Brooks and Suchey 1990). An age at death of approximately 30 years old strikes a balance between the various indications.

Table 12.4 Liang Lemdubu: morphology of Lemdubu Woman's pubic surfaces (Gilbert \& McKern criteria)

\begin{tabular}{|c|c|c|c|}
\hline SIDE & COMPONENT & STAGE & AGE MEAN AND RANGE \\
\hline Right & I & 4 & $40.8(28-59)$ \\
\hline Right & $\|$ & 3 & $38.8(27-57)$ \\
\hline Right & III & 4 & $39.9(21-58)$ \\
\hline Left & I & 3 & $31.0(22-40)$ \\
\hline Left & $\|$ & 3 & $38.8(27-57)$ \\
\hline Left & III & 3 & $35.6(22-57)$ \\
\hline
\end{tabular}

\section{Teeth}

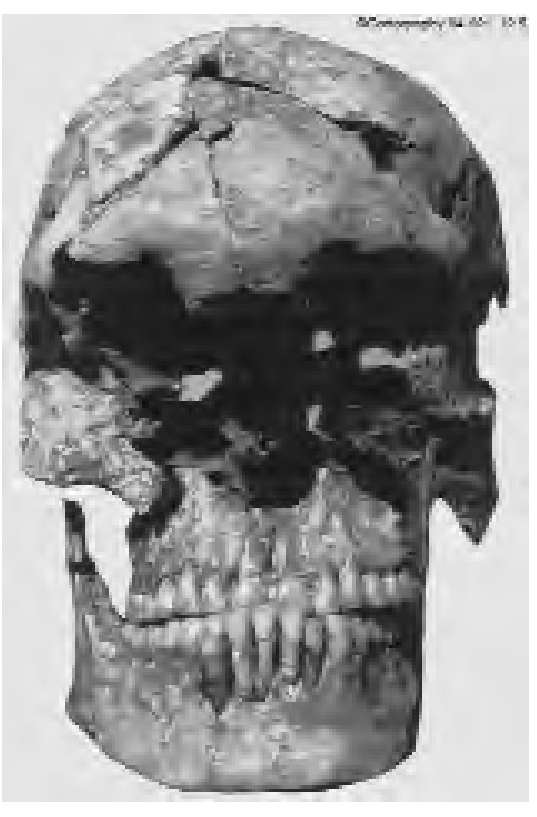

Figure 12.5 Liang Lemdubu: frontal view of the skull
Lemdubu Woman's occlusal wear is modest by hunter-gatherer standards. It almost always falls between the early stages of enamel polishing, especially on the upper third molars, and the exposure of small pools of dentine on the cusps, i.e. grades 2 or 3 wear in terms of Smith's scale (cf. Hillson 1996:232). More advanced wear was observed only on two of the first molars, in the form of an early stage of Smith's stage 4, involving slightly larger dentine pools on the buccal cusps. Interproximal wear on the teeth is slight but the individual's bite had nonetheless reached an edge-to-edge stage by the time of death (Fig. 12.5).

One of the second molars was evidently free of calculus, but otherwise slight calculus formation was observed on all of the teeth, and always at a coronal location (reflecting minimal resorption of the gums). Slight blunting resorption was noted at 15 of the tooth sites, involving all of the tooth classes between the incisors and the second molars. Slight buccal dehiscences were recorded at the sites of both lateral maxillary incisors, both maxillary canines, both first maxillary molars, and three of the premolars. Small interproximal septa were recorded at the site of the left lower canine, and in between the right upper premolars, the right lower premolars, and the lower left second premolar and first molar. Otherwise the extant alveolar bone looks in excellent condition, and no traces of caries were evident. At the time of her demise, Lemdubu Woman had had a sound and fully functional dentition.

The mesio-distal lengths and bucco-lingual breadths of the teeth were measured twice, in the first instance before they had been replaced in the jaws, and in the second instance (without reference to the original measurements) as members of the restored dentition. The mesio-distal measurements usually varied between the two occasions, with a discrepancy of up to $0.7 \mathrm{~mm}$, 
whereas the bucco-lingual diameters were identical on approximately half of the measurements, and, where they differed, did so by less than $0.2 \mathrm{~mm}$. The greater reliability of the bucco-lingual measurements thus provides another reason, in addition to their reduced alteration through interproximal wear (e.g. Brown 1992), to prefer them over mesio-distal diameters in drawing comparisons with neighbouring populations.

The size of the teeth of Lemdubu Woman (Table 12.5) may be regarded as approximately the same as the size of the mid-Holocene Flores male teeth. In the comparison with Leang Toge, which also is female, Lemdubu has larger mesio-distal lengths in 9/13 cases, and larger bucco-lingual breadths in 11/16 instances (Table 12.5). In the comparison with the 'other Flores' teeth, which are predominantly male - as most of the specimens with teeth are sexed as male and the others are unsexed (Jacob 1967:96-113) - any size discrepancy diminishes. The 'other Flores' teeth are larger on $6 / 16$ breadths (the more reliable comparison) and 8/16 lengths. If we compare cross-sectional tooth area (Brace and Hinton 1981), notwithstanding the uncertainty of relying on mesio-distal diameters, the value for Lemdubu Woman of $1353 \mathrm{~mm}^{2}$ is essentially indistinguishable from the value of $1358 \mathrm{~mm}^{2}$ for 'other Flores'. As demonstrated elsewhere, the middle Holocene Flores teeth are overall smaller than those of (mixed-sex) recent Australian Aborigines (Bulbeck 1981:Fig. 4-8).

Lemdubu Woman's tooth size falls broadly in between Australia's terminal Pleistocene (Coobool Creek/Kow Swamp) and recent average female tendencies, albeit showing the idiosyncratic variation to be expected of any individual. Seven of the teeth (in the premolar/upper first molar region) have breadths that exceed the averages in any comparative Australian series, contrasting with eight other teeth that have breadths beneath any comparative Australian average (Table 12.6). The overall slightly smaller tooth size than the values recorded for terminal Pleistocene Murray Valley Aboriginals could reflect individual, chronological and/ or geographic variation.

Morphological traits were recorded on the Lemdubu teeth according to the grades of the Arizona State University (ASU) system, with reference to the casts illustrating the standards for the various grades of expression wherever possible (Hillson 1996:85-102; Scott and Turner 1997:Chapter 2). Dental morphology is of limited value in determining an individual's affinities,

Table 12.5 Liang Lemdubu: diameters $(\mathrm{mm})$ of the burial's teeth (prior to replacement in the jaws) compared to midHolocene Flores average diameters (from Jacob 1967:82, 103)

\begin{tabular}{|c|c|c|c|c|c|c|c|c|}
\hline & \multicolumn{4}{|c|}{ MESIO-DISTAL LENGTHS } & \multicolumn{4}{|c|}{ BUCCO-LINGUAL BREADTHS } \\
\hline & LEMDUBU & LEMDUBU & LEANG & OTHER & LEMDUBU & LEMDUBU & LEANG & OTHER \\
\hline & LEFT & RIGHT & TOGE & FLORES & LEFT & RIGHT & TOGE & FLORES \\
\hline Upper central incisor & 9.1 & 8.7 & - & 8.4 & 7.3 & 7.4 & 7.1 & 7.7 \\
\hline Upper lateral incisor & 6.5 & 6.4 & - & 6.9 & 6.8 & 6.8 & 7.0 & 7.1 \\
\hline Upper canine & 8.3 & 8.8 & 8.1 & 8.4 & 8.7 & 8.7 & 8.55 & 9.1 \\
\hline Upper first premolar & 7.4 & 7.5 & 7.1 & 7.5 & 10.4 & 10.6 & 9.85 & 10.1 \\
\hline Upper second premolar & 7.3 & 7.6 & 6.7 & 7.5 & 10.5 & 10.7 & 10.15 & 10.1 \\
\hline Upper first molar & 11.6 & 11.5 & 10.2 & 10.9 & 13.2 & 13.3 & 11.65 & 12.1 \\
\hline Upper second molar & 9.8 & 9.3 & 9.9 & 10.0 & 12.8 & 12.6 & 11.95 & 11.9 \\
\hline Upper third molar & 8.7 & 8.5 & 8.5 & 10.1 & 11.9 & 11.8 & 11.85 & 11.7 \\
\hline Lower central incisor & 5.6 & 6.2 & 5.5 & 5.7 & 6.4 & 6.3 & 6.0 & 6.3 \\
\hline Lower lateral incisor & 5.6 & 7.0 & 6.5 & 6.1 & 6.1 & 6.4 & 6.4 & 6.7 \\
\hline Lower canine & 6.8 & 6.9 & 7.05 & 7.4 & 8.3 & 8.0 & 7.75 & 8.1 \\
\hline Lower first premolar & 7.8 & 7.6 & 7.3 & 7.2 & 8.7 & 8.9 & 8.6 & 8.5 \\
\hline Lower second premolar & 7.5 & 7.1 & 7.6 & 7.4 & 8.4 & 9.0 & 9.2 & 8.8 \\
\hline Lower first molar & 12.3 & 12.0 & - & 12.0 & 11.8 & 11.9 & 11.45 & 11.1 \\
\hline Lower second molar & 11.9 & 10.8 & 11.25 & 11.4 & 11.0 & 10.8 & 11.45 & 10.7 \\
\hline Lower third molar & 10.3 & 10.1 & 10.45 & 11.8 & 10.2 & 10.3 & 10.8 & 10.9 \\
\hline
\end{tabular}

NB: Flores diameters larger than the Lemdubu average are shown in bold face 
particularly as Pleistocene Australians have not (to my knowledge) been studied in this regard, and the differences between recent Australians and Southeast Asians in dental morphology are merely subtle (Bulbeck 2000a:Figs 4 and 5; Scott and Turner 1997:Fig. 7.5). The Aru individual's observations are presented here (Table 12.7) in the hope of contributing to a sample of comparable fossils as may become available at a future time.

Further observations include: slight bilateral winging of the upper central incisors but no winging of the lower central incisors; absence of any mesial ridging on the upper canines, or any

Table 12.6 Liang Lemdubu: tooth breadths compared to Australian Aboriginal female averages

\begin{tabular}{|c|c|c|}
\hline SIZE OF TOOTH & TEETH INVOLVED & No. \\
\hline Above both the Pleistocene and recent Australian averages, but still within the recent range & $\begin{array}{l}\text { Both } P^{1} \text {, both } P^{2} \text {, } \\
\text { both } M^{1}, R P_{1}\end{array}$ & 7 \\
\hline Equal to Pleistocene average, greater than recent averages & $\mathrm{R}$ lower $\mathrm{C}, \mathrm{R} \mathrm{P}_{2}$ & 2 \\
\hline Equal to Pleistocene and recent Australian averages which themselves barely differ & $\begin{array}{l}\text { Both } \underline{\mathrm{C}} \text {, both } \mathrm{I}_{1}, \mathrm{RI}_{2}, \mathrm{~L} \\
\mathrm{P}_{1} \text {, both } \mathrm{M}_{1}\end{array}$ & 8 \\
\hline Above recent averages but below Pleistocene average & Both $\mathrm{I}^{2}$, both $\mathrm{M}^{2}$ & 4 \\
\hline Within range of recent averages, smaller than Pleistocene average & Both $M^{3}$, L lower $C$ & 3 \\
\hline $\begin{array}{l}\text { Less than all Australian averages, sometimes beneath Pleistocene range (incisors) } \\
\text { but always within recent range }\end{array}$ & $\begin{array}{l}\text { Both } I^{1}, L I_{2}, L P_{2}, \\
\text { both } M_{2} \text {, both } M_{3}\end{array}$ & 8 \\
\hline
\end{tabular}

NB: comparative data from Brown (1989:144-157) with reference to samples having at least five measurements for the tooth concerned. The Pleistocene sample is Kow Swamp and coobool creek combined. $R$ denotes right and $L$ denotes left

Table 12.7 Liang Lemdubu: various dental morphological traits of Lemdubu Woman (ASU system)

\begin{tabular}{|c|c|c|c|c|c|c|}
\hline TRAIT & POSITION & LEFT & RIGHT & POSITION & LEFT & RIGHT \\
\hline Upper incisor shovel & Central & Trace (1) & Trace (2) & Lateral & Absent $(0)$ & Trace (1) \\
\hline Upper I double shovel & Central & Тгасе (1) & Trace (1) & Lateral & Absent $(0)$ & Absent (0) \\
\hline Upper I curvature & Central & $(2)$ & (3) & Lateral & (3) & (4) \\
\hline I tuberculum dentale & Central & (3) & (3) & Lateral & (3) & (2) \\
\hline l interruption groove & Central & Lateral & Lateral & Lateral & Lateral & Absent \\
\hline Lower incisor shovel & Central & Absent (0) & Absent (0) & Lateral & Absent (0) & Absent (0) \\
\hline Lower I curvature & Central & (1) & (2) & Lateral & $(2)$ & (3) \\
\hline Canine shovelling & Upper & Absent (0) & Absent (0) & Lower & Trace (1) & Trace (1) \\
\hline Distal accessory ridge & Upper & Absent $(0)$ & Absent (0) & Lower & Absent $(0)$ & Absent (0) \\
\hline C tuberculum dentale & Upper & (3) & (3) & Lower & (3) & (2) \\
\hline Premolar odontome & $p^{1}$ & Absent (0) & Absent (0) & $p^{2}$ & Absent (0) & Absent (0) \\
\hline Premolar odontome & $P_{1}$ & Absent $(0)$ & Absent (0) & $\mathrm{P}_{2}$ & Absent $(0)$ & Absent $(0)$ \\
\hline $\mathrm{P}$ accessory ridges & $p^{1}$ & Absent (0) & Absent (0) & $p^{2}$ & Absent (0) & Absent (0) \\
\hline $\mathrm{P}$ accessory ridges & $P_{1}$ & Absent (0) & Absent (0) & $\mathrm{P}_{2}$ & Absent $(0)$ & Absent $(0)$ \\
\hline $\begin{array}{l}\text { Premolar accessory } \\
\text { marginal tubercles }\end{array}$ & $p^{1}$ & Absent (0) & Absent (0) & $p^{2}$ & Absent $(0)$ & Absent (0) \\
\hline P lingual cusps & $P_{1}$ & Single & Single & $\mathrm{P}_{2}$ & Double & Double \\
\hline Upper M metacone & First & Full (5) & Full (5) & Second & Full (4) & Full (4) \\
\hline Upper M hypocone & First & Full (5) & Full (5) & Second & Full (4) & Full (4) \\
\hline Upper M metaconule & First & Absent $(0)$ & Absent (0) & Second & Trace (1) & Absent (0) \\
\hline$\underline{M}$ Carabelli's trait & First & Absent (0) & Absent (0) & Second & Absent $(0)$ & Absent $(0)$ \\
\hline Upper M parastyle & First & Absent (0) & Absent (0) & Second & Cingulum & Cingulum \\
\hline$\underline{M}$ enamel extension & First & Absent $(0)$ & Absent (0) & Second & Absent $(0)$ & Absent (0) \\
\hline Upper molar roots & First & Three & Three & Second & Two & ? \\
\hline Lower molar cusp 5 & First & Present (3) & Present (3) & Second & $?$ & ? \\
\hline Lower M cusps 6 \& 7 & First & Absent $(0)$ & Absent (0) & Second & Absent $(0)$ & Absent $(0)$ \\
\hline Dryopithecus pattern & First & Y & $Y$ & Second & $x$ & $x$ \\
\hline M enamel extension & First & Absent $(0)$ & Absent (0) & Second & Absent $(0)$ & Absent (0) \\
\hline Lower M protostylid & First & Absent (0) & Absent (0) & Second & Absent $(0)$ & Absent $(0)$ \\
\hline
\end{tabular}


distosagittal ridge on the first upper premolars, or size and shape diminution of the upper lateral incisors; and the single-rooted status of the lower canine and first lower premolar (both observed only on the right side). The upper third molars show slight metacone reduction (ASU 3) and considerable hypocone reduction (ASU 2 and 3), threshold expression of Carabelli's trait (ASU 1), no enamel extension but a unilateral (right) enamel pearl on the distal root, unilateral (left) trace presence of the metaconule, unilateral (right) expression of the parastyle as a faint cingulum, and a single root (observable only on the left side). The lower third molars have very large fourth cusps but no evidence of supernumerary cusps apart from a metaconulid on the right side. They also display an X Dryopithecus pattern bilaterally, absence of the anterior fovea or enamel extension, a unilateral (right) protostylid (ASU 3), and two roots on the left side (the only lower molar whose number of roots could be observed).

Of the observed traits, the upper incisor winging may be the most interesting as it tends to occur more commonly among East Asians (and Micronesians) than elsewhere in the world, especially compared to Australian and New Guinea people (Scott and Turner 1997:Fig. 5.2). However, it is hardly diagnostic, and all the other observations, including the tendency to mild shovelling on the anterior teeth, could be equally comfortably fitted within a southwest Pacific or Southeast Asian population affinity (cf. Scott and Turner 1997:Chapter 5).

Mildly expressed, single grooves and pitted lines of macroscopic enamel hypoplasia were noted on eight of the teeth (Table 12.8). The heights of the hypoplasic lines above the cervicoenamel junction of the crown were related to the enamel-defect matching system of Hillson (1996:Table 6.3). These observations provide sufficient evidence to recognise only one disruption to the individual's development that had resulted in interruption to enamel formation. That event, involving the first molars and central incisors, would be best interpreted as a Hillson ' $\mathrm{C}$ ' event, and involve a stage of dental development that would correspond to an approximate age of three to four years old. Mild physiological disruption associated with weaning, when the individual had to develop her own antibodies rather than rely on those from lactation, would provide a plausible explanation for these observations.

Table 12.8 Liang Lemdubu: macroscopic enamel hypoplasia observed on Lemdubu Woman

\begin{tabular}{lcccc}
\hline TOOTH & SEVERITY & HEIGHT (MM) & CROWN HEIGHT (MM) & POSITION \\
\hline${\text { Left } \mathrm{M}_{1}}^{\text {Right } \mathrm{M}_{1}}$ & Slight & 2.5 & $\sim 7.1$ & Intermediate \\
Left $^{1}$ & Slight & 2.2 & $\sim 7.0$ & Cervical \\
Left I $^{1}$ & Slight & 2.5 & $\sim 8.0$ & Cervical \\
Right I $^{1}$ & Moderate & 2.5 & 10.8 & Cervical \\
Left I $_{1}$ & Slight & 3.3 & 10.5 & Low intermediate \\
Right I $_{1}$ & Slight & 1.5 & 8.2 & Cervical \\
${\text { Left } M_{3}}$ & Slight & 2.5 & 8.7 & Cervical \\
\hline
\end{tabular}

\section{Cranial Morphology}

Observations on the cranial morphology of Lemdubu Woman were made predominantly following the system of Larnach and Macintosh (1966), as presented in Tables 12.3 and 12.9. Supplementary semi-discrete cranial traits were noted, where possible, according to the inventories listed by Kellock and Parsons (1971), Berry (1974), and Brothwell (1981:95), and are included in the textual description. Most of the utilized cranial measures are those employed by Pietrusewsky (1984:55), including those in Martin's system (Martin and Saller 1957:453-81), which are denoted with an ' $\mathrm{M}$ ' in brackets in Table 12.10. Other measurements come from Howells 
Table 12.9 Liang Lemdubu: craniomorphological observations of Lemdubu Woman following Larnach and Macintosh (1966)

\begin{tabular}{|c|c|c|c|}
\hline TRAIT & EXPRESSION & TRAIT & EXPRESSION \\
\hline Cranial index & Mesocranic & Cranial contour & 0void \\
\hline Brow ridge type & Divided & Maximum supraborbital breadth & Large \\
\hline Supraglabellar fossae & Medium & Ophrionic grooves & Medium \\
\hline Temporal crests & Slight & Median frontal ridge & Absent \\
\hline Supraorbital notches & Marked & Supraorbital foramina & Absent \\
\hline Frontal recession & Slight & Naso-frontal articulation width & Very broad \\
\hline Anterior nasal spine shape & Pointed & Anterior nasal spine size & Between Broca 1 \& 2 \\
\hline (R) infra-orbital fossa depth & 8mm (deер) & Anterior narial margins & $\begin{array}{l}\text { Type } 2 \\
\text { (non-anthropine) }\end{array}$ \\
\hline Subnasal prognathism & Large & Orbital border of malar bones & Rounded \\
\hline Size of right malar bone & Large & $\begin{array}{l}\text { Inferior margin of zygomatic process } \\
\text { of }(R) \text { maxilla }\end{array}$ & Markedly concave \\
\hline (L) auditory exostoses & Absent & (L) external auditory meatus & Martin 3 \\
\hline (R) tympanic bone thickness at meatus & Thick & Glenoid fossa depth & $7.5 \mathrm{~mm}(\mathrm{R}) ; 8 \mathrm{~mm}(\mathrm{~L})$ \\
\hline (L) suprameatal ridge & Marked & (R) postglenoid tubercle & Large \\
\hline (L) mastoid crest & Marked & (R) foramen of Huschke & Absent \\
\hline (L) digastric fossa & Medium & (L) occipito-mastoid crest & Large \\
\hline (L) angular torus & Absent & (L) supramastoid crest & Slight \\
\hline Sagittal keeling & Trace & Pterion region articulation & Spheno-parietal \\
\hline Parietal bosses & Large & Parietal foramina & Absent \\
\hline Obelionic depressions & Slight & Occipital bun & Large \\
\hline Inca bone & Absent & Supra-iniac fossa & Very small \\
\hline Sulcus supratoralis & Absent & Transverse occipital torus & Trace ridge \\
\hline (L) foramen ovale development & Complete & $\begin{array}{l}\text { Foramen spinosum development \& } \\
\text { confluence with } f \text {. ovale }\end{array}$ & $\begin{array}{l}\text { Complete; } \\
\text { no confluence }\end{array}$ \\
\hline (L) palatine torus & Large ridge & (L) transverse palatine suture direction & Anterior \\
\hline Palate shape & Borderline mesuranic & Palate shape & Parabolic (L); elliptical (R) \\
\hline
\end{tabular}

NB: seven further traits are presented in Table 12.3. ( $R$ ) indicates right side, and $(\mathrm{L})$ indicates left side

Table 12.10 Liang Lemdubu: cranial measurements $(\mathrm{mm})$ and main derivative expressions of Lemdubu Woman

\begin{tabular}{|c|c|c|c|}
\hline Maximum cranial length (M1)* & 179.0 & Nasi-occipital length (M1d) & 172.5 \\
\hline Maximum cranial breadth (M8)* & 140.0 & Basion-bregma cranial height (M17)* & 133.5 \\
\hline Basion-nasion length (M5) & 89.0 & Bi-auricular breadth (M11b): & 120.0 \\
\hline Bi-asterionic breadth (M12) & 107.0 & Maximum frontal breadth (M10) & 111.0 \\
\hline Minimum frontal breadth (M9) & 95.0 & Bi-stephanic breadth (M10b) & 108.0 \\
\hline Minimum cranial breadth (M14) (S) & $\sim 70.0$ & Minimum cranial breadth (WCB) (S) & $\sim 66.0$ \\
\hline Nasion-bregma chord (M29)" & 107.0 & Frontal subtense (FRS, LM) & 29.0 \\
\hline Frontal fraction (FRF) & 40.0 & Bregma-lambda chord (M30)" & 117.0 \\
\hline Parietal subtense (PAS) & 24.0 & Parietal fraction (PAF) & 56.0 \\
\hline Mastoid height (MDH): & 29.0 & Mastoid breadth (MDB) & 14.0 \\
\hline Mastoid antero-posterior diam. (LM) & 30.0 & Nasofrontal articulation width (LM) & 23.0 \\
\hline Glabella subtense (GLS) & 6.0 & Supraorbital subtense (SOS) & 8.5 \\
\hline Max. supraorbital diameter (M43)* & 111.0 & Fronto-malar breadth (FMB) & 103.0 \\
\hline Nasio-frontal subtense (NAS) & 12.0 & Nasal breadth (M54) & 26.0 \\
\hline Bimaxillary breadth (M46) (S) & $\sim 97.0$ & Zygo-maxillary breadth (ZMB) (S) & $\sim 100.0$ \\
\hline Cheek height (M48(4)) (R) & 21.5 & Cheek height (WMH) (R) & 21.0 \\
\hline Palate length (M60) & 60.0 & Palate breadth (M61): & 69.0 \\
\hline Palate module (M60 x M61/100) & 41.4 & Palate index (100M61/M60) & 115.0 \\
\hline Palate depth (LM) & 13.0 & Frontal index (100FRS/M29) & 27.1 \\
\hline Mastoid process module (LM) & 121.8 & Cranial index (100M8/M1) & 78.2 \\
\hline
\end{tabular}

NB: (S) indicates that symmetry of the cranium was assumed to make the resulting approximate measurement. (R) indicates measurement on the right side; otherwise, the left side was used for unilateral variables. Asterisked measurements appear in the FORDISC 2.0 analysis (below) 
(1973:163-83; marked by their three-letter acronym), and Larnach and Macintosh (1966:82-3; denoted 'LM' in Table 12.10).

The skull's masculine appearance stems from the strong development of the glabella, superciliary ridges and zygomatic trigone, the large diameter across the supraorbital region, the very large mastoid process whose module of ca. 122 is obtained from multiplying its three diameters, and the large palate (Figs 12.5, 12.6; Tables 12.3, 12.9, 12.10). The brow-ridge morphology arises from the bilaterally large frontal and nasal sinuses, covered by thin bone. The frontal sinuses are approximately $18 \mathrm{~mm}$ deep antero-posteriorly, and around $15-24 \mathrm{~mm}$ wide. The slightly asymmetric, left-skewed shape of the brows is also evident in the sinuses, so that the left nasal sinus articulates with the left

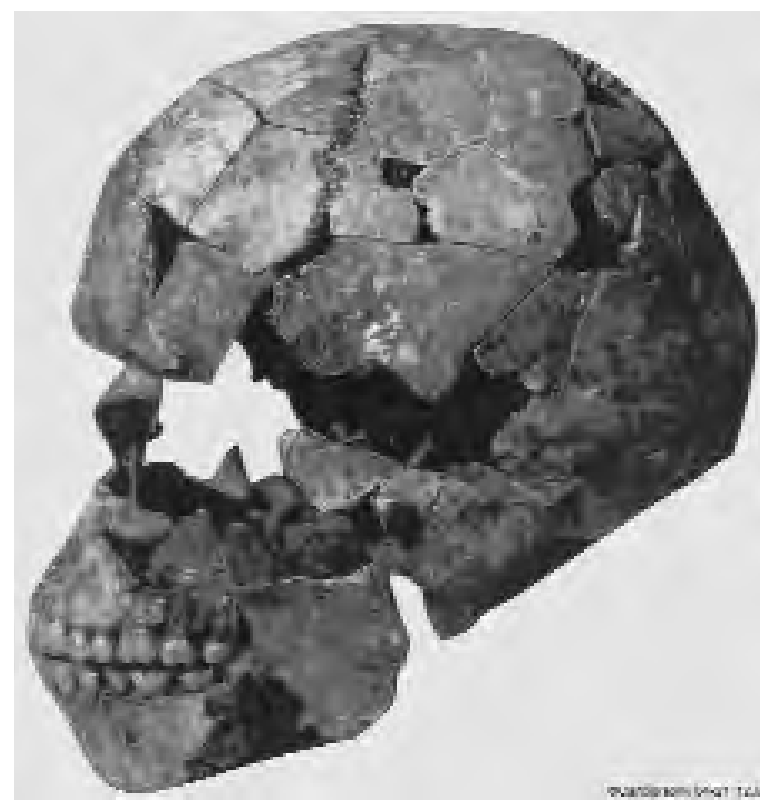

Figure 12.6 Liang Lemdubu: left lateral view of the skull frontal sinus, and its antimere lies under the nasal saddle rather than on the right side. Slight metopism is present in the form of a remnant frontal suture running from nasion to a point $20 \mathrm{~mm}$ supero-posterior of glabella. Frontal foramen and frontal groove/notch are absent.

The frontal bone is well-vaulted, as shown by its curvature index of 27.1, but also angled in lateral view, owing to a flattened plane immediately anterior of bregma. The contour of the posterior braincase is even more sharply angled, owing to a steeply dropping occipital plane immediately posterior to the most bulging point along the parietal midline, and the large occipital bun. Poor preservation of the bone beneath the weakly developed, transverse occipital torus prevents any observation on the external occipital protuberance or the nuchal markings. However, absence of a highest nuchal line can be recorded on the left side, at least, and the inion region lacks any emissary foramen.

In superior view the cranium has a moderately short, ovoid shape, as the parietal bosses cover a large area but are not especially prominent. In contrast to the open ectocranial status of the coronal, sagittal and lambdoid sutures, the occipito-mastoid suture shows incipient obliteration. Parietal foramina, sagittal ossicles and a bregmatic bone are all absent. Medially, the lambdoid sutures are simple, without any signs of ossicles at lambda or an Inca bone. Laterally, however, these sutures become complicated, leading to the expression of single lambdoid ossicles $17 \mathrm{~mm}$ medially of the asteria, and on the left side (which is observable), a biasterionic suture $20 \mathrm{~mm}$ long, an asterionic bone, and occipito-mastoid wormian bones. The left mastoid region is extant and shows a moderately rugged morphology (see Table 12.9), a mastoid groove, mastoid notch, and a mastoid foramen which does not however occupy an extra-sutural position. The glenoid fossa has a normal morphology bilaterally (cf. Richards and Brown 1981) and, at least on the right side, is of normal form without any tympanic dehiscence. Other traits observable on the right include the single and unbridged hypoglossal canal, the single condylar facet, and the absence of any paracondylar process, precondylar tubercle, or intermediate condylar canal. On the left side, the foramen spinosum is closed without any accessory expression of this foramen or confluence with the spinosum laterale.

When the face is joined to the calvarium, it is clearly short and prognathic, with broad orbits and nasal aperture, even if few facial measurements can be accurately taken. As shown on the right side, the malar bone has a rough lower masseteric border and a single zygomatico-facial foramen, 
there are no maxillary hyperostoses on the buccal aspect of the alveolar arcade, and cribra orbitalia is present as a weak, trabecular development. This condition of partly healed cribra orbitalia would represent a probably mild bout of anaemia during childhood, most likely associated with physiological insult suffered at the time of weaning (cf. Webb 1995:93-9). Small maxillary hyperostoses can be observed bilaterally on the lingual aspect of the palate above the second molar. Finally, the left middle meningeal artery on the endocranial surface would be classified as Type 1 in Giuffrida-Ruggeri's system, whereas the right middle meningeal artery would more probably register as Type 2 (cf. von Bonin 1963:47-8). These Type 1 and 2 patterns appear to be the most common variants among recent East Asian and Pacific populations, with the possible exception of Polynesians (Bulbeck 1981:342).

The cranial bone is thin with a very thin inner table which is generally about half the thickness of the outer table, the latter $30-60 \%$ of the thickness of the diploe. Thicknesses at landmarks include $10.1 \mathrm{~mm}$ at nasion, $11.3 \mathrm{~mm}$ at glabella, $6.3 \mathrm{~mm}$ at bregma, $5.6 \mathrm{~mm}$ at right euryon, $5.1 \mathrm{~mm}$ at left euryon, and about $6.0 \mathrm{~mm}$ at the frontal bosses. These euryon, bregma and frontal thicknesses barely differ from those of Lake Mungo 1 (Willandra Lakes 1, WL1) which is renowned in the annals of Australian palaeoanthropology for its thin cranial bone (e.g. Brown 1987:49). Lemdubu Woman's skull bone thicknesses are consistently smaller than those of WL3, WL130, and especially WL19 (cf. Webb 1989:24), which are all fossil crania of small size (Bulbeck 2001:Figs 4 and 5) but which have moderate to thick cranial bone by Willandra Lake standards. Even by recent, female Aboriginal standards (Brown et al. 1979), the Lemdubu braincase registers very low nasion and bregma thicknesses, although euryon thickness is high. Its combination of thin cranial bone and relatively rugged morphology disputes the relationship between robustness and cranial bone thickness proposed by Thorne (1977) and Webb (1989:74) for Pleistocene Sahulland people.

\section{Cranial Size}

During her PhD studies at the Australian National University, Catherine Willis (1998) developed a technique to gauge cranial size, subsequently refined by the author (Bulbeck 2001). Only female crania will be considered here, but the technique would be the same for males. On any compared measurement, a cranium is classified either as very small (scoring 1), small (scoring 2), large (scoring 3), or very large (scoring 4), in comparison to recent Australian Aborigines. A measurement is 'very small' when it is smaller than the smallest value two standard deviations below the mean recorded by either Pietrusewsky (1984) or Brown (1989) on each and every mainland Australian series. 'Small' means a measurement between that value and the grand Australian mean as found by either Pietrusewsky or Brown (as appropriate). 'Large' means a measurement above the grand Australian mean, but not exceeding the mean of all the Australian series by more than two standard deviations, while 'very large' means greater than two standard deviations beyond any recorded mainland Australian mean. At least three measurements must be available for a specimen to be included. The cranium's scores, between 1 and 4, are tallied and divided by the number of measurements to produce an overall assessment of cranial size; Lemdubu Woman for instance scores $45 / 15$ or 3.0 (Table 12.11).

The distribution of recent Australian, female cranial size is obtained by assessing all 382 adult female crania with three or more measurements published by Hrdlička (1928). Cranial size ranges between approximately 1.8 and 3.3, with an average (as expected) at about 2.5; the modal class coincides with the average as would be expected of a normal curve, which the distribution resembles albeit with some irregularities (Fig. 12.7). As previously established (Bulbeck 2001), all Late Pleistocene to early Holocene Australian crania — both male and female — differ from recent Australians in being larger, with their size lying above the recent mean, and the largest individuals lying either at the highest extreme of the Australian range or, very occasionally, beyond it. 
Table 12.11 Liang Lemdubu: Lemdubu Woman in relation to boundary values for very small (below $<2$ SD), small ( $<2$ SD to Mean), large (Mean to >2 SD), and very large (over >2 SD) Australian female crania

\begin{tabular}{|c|c|c|c|c|c|}
\hline MEASUREMENT & $<2 S D$ & MEAN & $>2 S D$ & LEMDUBU (MM) & LEMDUBU SCORE \\
\hline Maximum cranial length (P) & 161.7 & 178.0 & 193.0 & 179 & 3 \\
\hline Maximum cranial breadth $(P)$ & 112.1 & 125.4 & 136.1 & 140 & 4 \\
\hline Basion-bregma height (P) & 114.7 & 127.3 & 137.2 & 133.5 & 3 \\
\hline Basion-nasion length (P) & 88.9 & 96.2 & 107.7 & 89 & 2 \\
\hline Basion-prosthion length (M40) (B) & 88.9 & 100.2 & 111.5 & - & - \\
\hline Bi-auricular breadth (P) & 101.3 & 112.1 & 122.8 & 120 & 3 \\
\hline Bi-asterionic breadth $(\mathrm{P})$ & 90.9 & 102.2 & 114.9 & 107 & 3 \\
\hline Minimum frontal breadth (P) & 84.1 & 93.1 & 105.0 & 95 & 3 \\
\hline Bi-stephanic breadth (P) & 87.2 & 100.2 & 113.8 & 108 & 3 \\
\hline Nasion-bregma chord (P) & 96.3 & 106.7 & 121.2 & 107 & 3 \\
\hline Bregma-lambda chord (P) & 98.9 & 111.3 & 125.5 & 117 & 3 \\
\hline Lambda-opisthion chord (M31) (P) & 80.6 & 90.9 & 103.9 & - & - \\
\hline Max. supraorbital diameter $(P)$ & 95.5 & 103.1 & 112.2 & 111 & 3 \\
\hline Bi-orbital breadth (EKB) (P) & 89.6 & 96.7 & 104.9 & - & - \\
\hline Bimaxillary breadth (M46) (P) & 76.8 & 89.5 & 103.1 & 97 & 3 \\
\hline Bizygomatic breadth (M45) (B) & 116.5 & 126.8 & 138.1 & - & - \\
\hline Nasion-prosthion (M48) (P) & 52.4 & 62.2 & 71.7 & - & - \\
\hline Nasal height (M55) (P) & 40.1 & 47.7 & 53.7 & - & - \\
\hline Nasal breadth $(P)$ & 21.3 & 25.4 & 30.2 & 26 & 3 \\
\hline Orbital breadth (M51a) (B) & 39.0 & 42.2 & 45.6 & - & - \\
\hline Orbital height (M52) (P) & 27.3 & 32.7 & 38.1 & - & - \\
\hline Palate (alveolar) length (B) & 52.6 & 58.6 & 65.6 & 60 & 3 \\
\hline Palate (alveolar) breadth (P) & 49.7 & 62.4 & 70.3 & 69 & 3 \\
\hline
\end{tabular}

NB: comparative Australian Aboriginal size ranges from Pietrusewsky (1984:Tables 7, 9), indicated (P) except where unavailable, in which case size ranges are from Brown's (1989) series, indicated (B), where the sample size of measurements is greater than 14

Accordingly, if Lemdubu Woman was a Late Pleistocene inhabitant of Sahulland age, its size should be comparable to the size of Late Pleistocene or early Holocene, female Australian crania. On the other hand, a middle Holocene antiquity for the Lemdubu burial would be confirmed if it is found to resemble Leang Toge in cranial size.

In this comparison, Leang Toge's measurements are taken from Jacob (1967:97-8), except for alveolar length, which is given by Storm (1995:178). For fossil Australians, preference is given to Pietrusewsky's and Brown's measurements where possible, as their measurements are used in establishing size-assessment boundaries. Pietrusewsky's measurements (reproduced in Willis 1998:20-35) are used for Kow Swamp females (sexes given in Thorne 1975:A79). Measurements on individual Coobool Creek females are taken from Brown (2001), despite the potential risk of using data privately published via the internet. The measurements for WL3 also come from Brown (1989:46-7), but for the other Willandra Lake females (WL45 and WL130), we need to turn to Webb (1989:45).

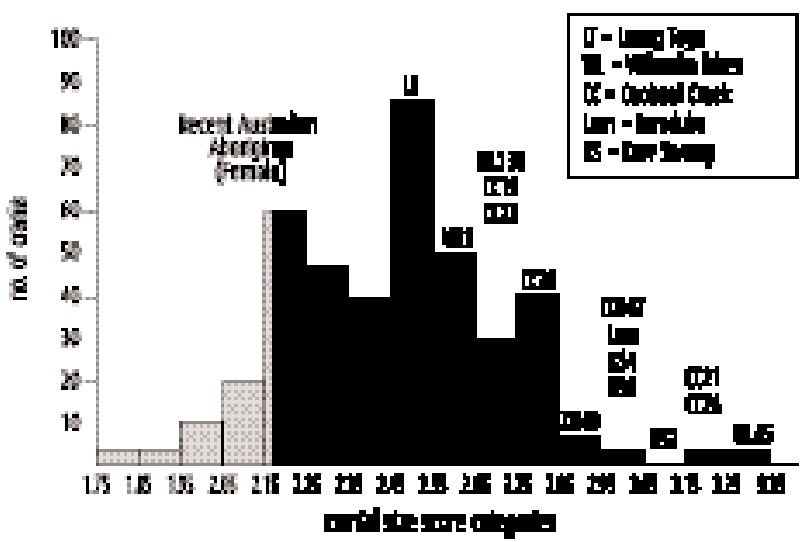

Figure 12.7 Liang Lemdubu: cranial size of Leang Toge, Lemdubu and Australian female fossils compared to recent Australian Aborigines 
Note that this comparison excludes Lake Mungo 3 (WL3), notwithstanding Brown's (2000) doubts over the male status conventionally assigned to this burial. The fact that its ulna length of $297 \mathrm{~mm}$ lies near the top of the recent Aboriginal male range and well above the female range (Brown 2000:747; Rao 1966:267) will be accepted here as demonstrating the burial's male status. Brown argues that regression formulae developed on black South African ulnae would produce an estimated stature for WL3 barely greater than the recent Aboriginal male average, and within the Late Pleistocene female range. However, even assuming that these regression formulae are appropriate for Australians, it is well known that least-squares regression estimates made from the dependent to the independent variable, stature in this case, are biased in systematically dragging the estimates back towards the reference population's mean value (Formicola 1993). Note also that the King Island burial is excluded regardless of whether it is female (Brown 1994, 1995) or male (Thorne and Sim 1994). Several of the measurements given by Sim and Thorne (1990) are obviously unreliable: the combination of an extremely long nasion-bregma chord $(130 \mathrm{~mm})$ with an anomalously short bregma-lambda chord (94mm) (cf. Table 12.11); and fibula mid-shaft measurements which would minimally lead to a diameter of $82 \mathrm{~mm}, 13$ standard deviations above the male Australian mean (cf. Rao 1966:272). Whether the cause for these anomalies is the very brief period of three hours available to inspect the burial (Brown 1994), poor proof reading, or remarkably deviant skeletal morphology, Sim and Thorne's published measurements are difficult to use with confidence.

Lemdubu Woman's score of 3 on overall cranial size is very typical of early Australian fossils, whereas Leang Toge's score of 2.55 approximates the recent Australian female average, and is smaller than the result found for any early Australian female (Fig. 12.7). Accordingly, the similarity in cranial size that would be expected if the Lemdubu and Leang Toge crania were of the same middle Holocene age is disproved, and instead we conclude that Lemdubu Woman had the large cranial size expected of a Pleistocene Sahulland inhabitant.

\section{Cranial Comparisons}

Craniometric comparisons are made here to the worldwide coverage of recent populations by Howells (1973:193-238), as mediated through FORDISC 2.0 (Ousley and Jantz 1996). Eleven measurements from the Lemdubu skull may be used in this analysis, as asterisked in 12.10. As the Lemdubu cranial measurements regularly exceed the recent Australian female average (Table 12.11), they should arguably be compared with recent male as well as female craniometrics as a check that any identified similarities are not dominated by size effects. Leang Momer E, a middle Holocene male skull from Flores, is included in this analysis along with Leang Toge. Eighteen measurements are available for both Leang Momer E and Leang Toge, preferentially from Jacob $(1967: 80,97-8)$ but otherwise from Storm $(1995: 169,178-9)$. Our expectation is that Lemdubu should affiliate with Howells' southwest Pacific populations if the chronological determination making it a Pleistocene inhabitant of Sahulland is correct. If that result is obtained, and the compared Flores specimens do not resemble Howells' southwest Pacific populations, then the case is further strengthened for assigning Lemdubu Woman and the inhabitants of middle Holocene Flores to chronologically distinct populations.

FORDISC 2.0 usefully provides both 'typicality' and 'posterior' probabilities. Typicality essentially registers the likelihood of a specimen with the said measurements belonging to any given comparative population, while posterior probability estimates are based on the assumption that the specimen must belong somewhere among the recent comparative series. The typicality probabilities need not delay us long as they are always low. Leang Momer E has the highest, with a $5.0 \%$ probability of being Hawaiian, $4.4 \%$ of being South Japanese, $3.4 \%$ of being a Teita, and lower 
probabilities otherwise. Lemdubu would have a $1.4 \%$ probability of being a Tasmanian male, and a $0.1 \%$ to $0.5 \%$ probability of being a male Tolai, !Kung, Zulu, South Australian or Andaman Islander. Lemdubu (and Leang Toge) registers $0.0 \%$ probabilities of belonging to any of Howells's recent female series, confirming its large cranial size by recent female standards.

With the posterior probabilities, Lemdubu is much more similar to Tasmanians than to any other of Howells' populations, although the Tolai from New Britian and southern African !Kung emerge as remote affinities (see Table 12.12). This result is consistent with a terminal Pleistocene Sahulland status for Lemdubu Woman, given that Pietrusewsky (1984:Fig. 4) similarly found a remote craniometric relationship between Kow Swamp and Tasmanians.

The suggested affinities of the Flores crania are less clear. Both find their nearest match with 'Mongoloid' groups, Polynesians (and Japanese) in the case of Leang Momer E, and Eskimos in the case of Leang Toge (Table 12.12). But there would be little to choose between Eskimos, South Australians, and Melanesians in identifying Leang Toge's closest resemblance. This latter point is the only craniometric result that lends any support at all to Jacob's (1967:114) claim for a Melanesian element in the mid-Holocene inhabitants of Flores. The Aru specimen on the other hand is definitely closer to southwest Pacific populations than any others in its craniometrics, reinforcing its status as a representive of the Pleistocene population of Sahulland. A further feature that reinforces the same impression is the angular contour of Lemdubu Woman's braincase, a trait shared with most Coobool Creek and related ancient crania from southeastern Australia (Brown 1982:202-4; Webb 1989:Fig. 12.1), in contrast to the more rounded countours of Leang Momer E and Leang Toge (Storm 1995:Figs 23 and 25).

Comparisons involving relevant selections of Larnach and Macintosh's 'race discrimination traits' reiterate the same conclusion. For these comparisons, Queensland Aboriginal males are taken from a photocopy of Larnach's original records (see Larnach and Macintosh 1970). Melanesians include Johan Kamminga's observations on New Caledonia males and the author's observations on Solomon Island crania, while the Java/Malay all-male sample was recorded by Kamminga in the British Museum of Natural History (see Bulbeck 1981:278). Kamminga's observations on Leang Momer E and Leang Toge (reported in Bulbeck 1981:325-40) are also included here.

The first comparison involves glabella prominence, superciliary ridge development, zygomatic trigone size, palate size, frontal recession, maximum supra-orbital breadth, and cranial index, employing the grade boundaries and scoring system of Larnach and Macintosh (1966:82-3). The justification for this choice of traits is that Brown (1982:Appendix 3) recorded them on Coobool Creek and Murray Valley (including Swanport) Aborigines. Two male Kow Swamp crania, KS1 and KS5, are also recorded on all seven traits (Thorne 1975:189-90, A79). However, females need to be treated in this analysis separately from males as most of the traits show marked sexual dimorphism. Characteristically Australian (masculine) expressions score 3, non-Australian expressions score 1, and ambiguous expressions score 2, so that when the individual specimens'

Table 12.12 Posterior probabilities greater than $10 \%$ (in bold face) comparing the Liang Lemdubu and Flores fossil crania with Howells's recent populations

\begin{tabular}{|c|c|c|c|c|}
\hline RECENT SERIES & LEMDUBU (CF. FEMALES) & LEMDUBU (CF. MALES) & LEANG MOMER E & LEANG TOGE \\
\hline Tasmanians & 0.556 & 0.588 & 0.001 & 0.000 \\
\hline Eskimos & 0.000 & 0.000 & 0.072 & 0.328 \\
\hline South Australians & 0.014 & 0.006 & 0.000 & 0.282 \\
\hline Tolai & 0.158 & 0.151 & 0.049 & 0.257 \\
\hline Hawaiians & 0.000 & 0.000 & 0.244 & 0.000 \\
\hline South Japanese & 0.005 & 0.002 & 0.192 & 0.000 \\
\hline Zulu & 0.042 & 0.030 & 0.020 & 0.127 \\
\hline San !Kung & 0.105 & 0.120 & 0.023 & 0.000 \\
\hline Teita & 0.000 & 0.000 & 0.113 & 0.002 \\
\hline
\end{tabular}


scores are added across the traits, Australian Aborigines tend to score higher than Melanesians who in turn score higher than Indonesians (Fig. 12.8).

All the fossil Australian crania fall within the top half of the recent Australian range, bar one Coobool Creek female. The same generalisation would also apply to the Lemdubu cranium which, indeed, lies above the recorded Melanesian range. Leang Momer E and Leang Toge, by contrast, fall comfortably within the Melanesian range, which is the same result that I have found when assessing other pre-Neolithic to Iron Age, Indonesian and Malaysian crania in terms of Larnach and Macintosh's traits (Bulbeck 1981:Figs 7-3 to 7-10). These results confirm the making of a clear distinction between Lemdubu Woman - who should be thought of simply as an ancient Australian - and the Flores specimens, which behave in the same way as other prehistoric Southeast Asian crania located to the west of the Sahul shelf.

The second comparison focuses on those traits with little or no sexual dimorphism: cranial index, parietal bossing, transverse occipital torus development, sagittal keeling, median frontal ridge expression, frontal recession, naso-frontal articulation width, malar orbital boder rounding, anterior nasal spine morphology, subnasal prognathism and palatine torus expression. In some of those traits, Larnach and Macintosh accord ' 0 ' to non-Australian expressions and ' 1 ' to ambiguous developments; otherwise, methodology is the same as in the previous comparison. In this case, Melanesian males and females do not seem to differ appreciably, suggesting that sex has been nullified as a relevant factor (Fig. 12.9). The expanded array of traits disqualifies Kow Swamp, Leang Momer, and Brown's observations from inclusion; otherwise, the same sources are availed as in the first comparison.

Figure 12.9 produces the sort of result typically found for prehistoric Southeast Asians (Bulbeck 1981:Figs 7-3 to 7-10), with Lemdubu Woman and Leang Toge both lying near the midpoint of the recent Melanesian range (and, in this instance, above the Java/Malay range). The Lemdubu and Leang Toge specimens behave similarly here, in contrast to their marked separation in the first comparison, because these specimens' differences are concentrated on sexually dimorphic traits - those that involve size and related robustness. When ca. 10,000 year old Murray Valley Aborigines are compared with their recent (and presumably descendant) counterparts, their cranial differences are also predominantly a function of size and robustness (Brown 1987). By analogy, it may also be suggested that Lemdubu Woman could represent the population broadly ancestral to the middle Holocene population represented by the Flores crania.

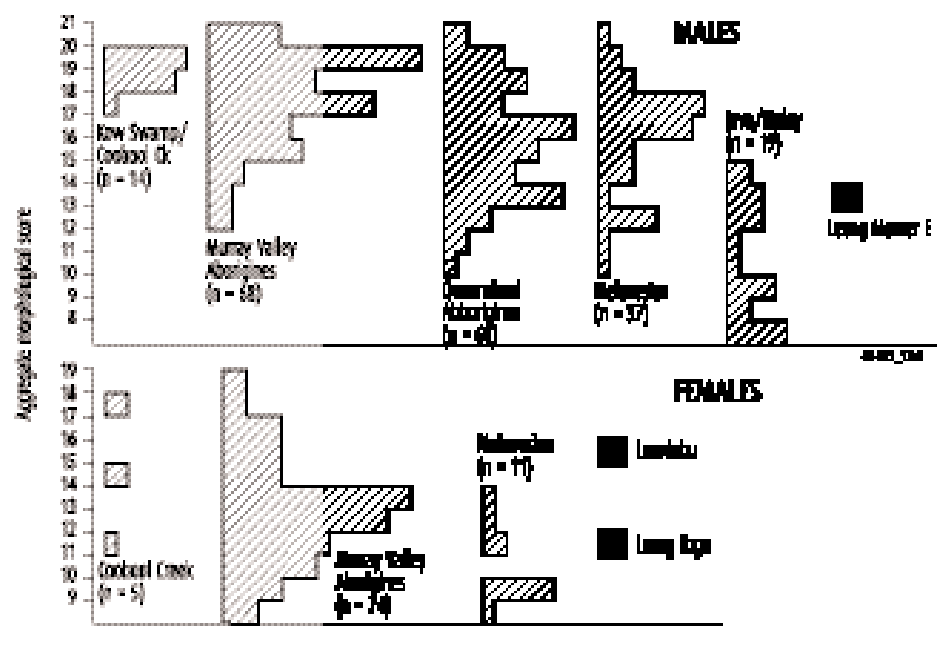

Figure 12.8 Australasian recent crania and prehistoric fossils compared on seven morphological traits

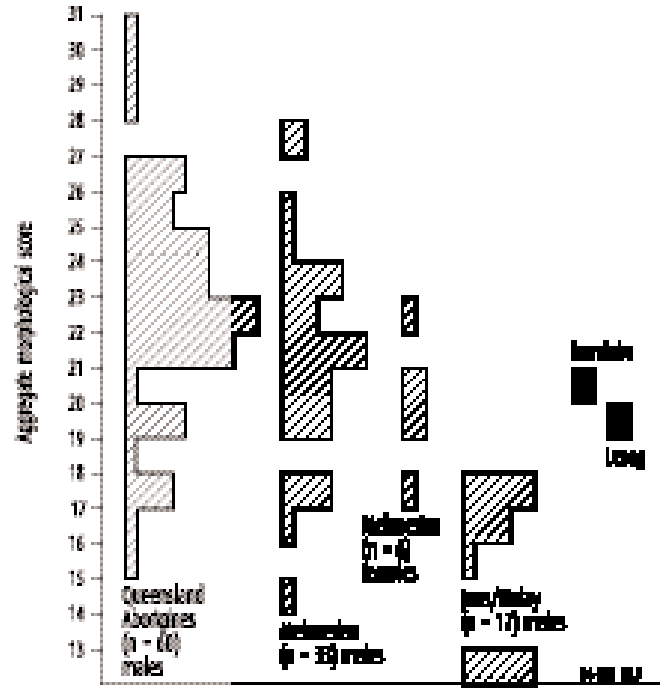

Figure 12.9 Australasian recent crania and prehistoric fossils compared on less sexually dimorphic characters 


\section{Mandibular Morphology}

The Lemdubu mandible (see Fig. 12.10 and Table 12.13) is of masculine morphology by recent Australasian standards, to follow Larnach and Macintosh's (1971:31) standards for sexing mandibles. In addition to the large bigonial breadth and minimum ramus breadth (scoring 3 each), and the medium symphysis height (2), Lemdubu has a large planum triangulare area and everted gonia ( 3 each), though its anterior marginal tubercle is merely slight on the left side and medium on the right (1.5), and the sulcus intertoralis is bilaterally slight (1). Even if the Lemdubu mandible is given a score of 1 for the four Larnach and Macintosh traits which are not extant on this specimen, its resulting score of 20.5 would lie comfortably above the lower boundary of 19 recognised by Larnach and Macintosh (1971:33) and Bulbeck (1981:489) for male Australasian mandibles.

The following morphological traits on the Lemdubu mandible were also recorded in terms of Larnach and Macintosh's (1971) grades. On the right side, the sulcus extramolaris is slight, the lateral prominence is marked, and the posterior marginal tubercle is prominent. The superior lateral torus and marginal torus show medium development bilaterally, while the single mental foramen lies beneath the second molar on both sides. The chin region includes a large trigonum mentale but nonetheless has negative projection owing to the medium decline of the planum alveolare and the medium anterior mandibular incurvature. There is a slight submental notch, a slight trigonum basale and a faint sulcus praedigastricus, but no trace of any superior transverse torus, and the fossae mentalis are bilaterally slight. Genial pit is absent whereas the genial spines are large. Moving posteriorly we remark bilaterally marked digastric fossae and submaxillary fossae, but the absence of any sublingual fossae. The mylohyoid ridge is large bilaterally but there is no sign of a mandibular torus. At the rear of the dental arcade, the bilaterally trace crista pharyngea couples with precoronoid fossae of medium depth. On the left side we may note the marked mylohyoid groove, trace lingula, slight sulcus colli and marked crista endocoronoidea on the medial surface of the ramus. The lateral face of the ramus exhibits a more or less flat fossa masseterica, and a marked torus triangularis.

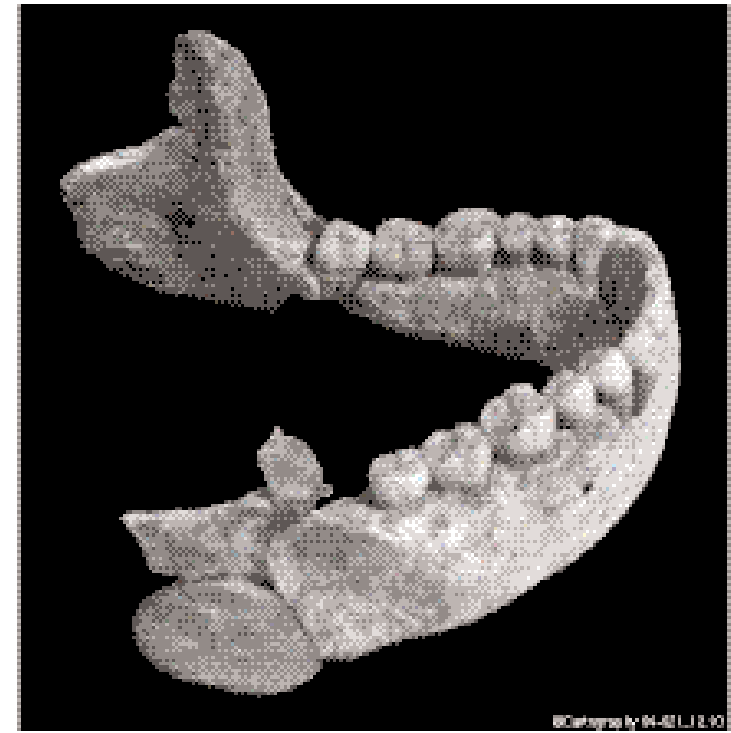

Figure 12.10 Liang Lemdubu: the mandible in oblique superior view

Table 12.13 Liang Lemdubu: mandibular measurements (mm)

\begin{tabular}{|c|c|c|c|}
\hline Bigonial breadth $(M 66$, w2): & 99.5 & Bigonial width $\left(g_{0} g_{0}\right)$ & 96.0 \\
\hline Bicoronoid breadth $\left(M 65(1), c_{r} C_{r}\right)(S)$ & $\sim 88.0$ & Corpus length (M68, cpl) (S) & $\sim 94.0$ \\
\hline Chin height $(M 69, \mathrm{~h} 1)^{*}$ & 29.0 & Symphysis height (LM) & 30.5 \\
\hline Bimental breadth (zz) & 45.5 & Interobliqual breadth (Jacob) & 81.0 \\
\hline Corpus height at mental foramen (M69 (1)) & 30.5 & Corpus breadth at mental foramen (M69 (3)) & 12.0 \\
\hline Corpus height between first and second molar (0livier) (R)* & 26.5 & Corpus thickness between first and second molar (0livier) (R)* & 15.0 \\
\hline Molar-premolar chord $\left(\mathrm{m}_{2} \mathrm{p}_{1}\right)$ & 25.0 & Gnathion-gonion length (gngo) & 90.0 \\
\hline Minimum ramus breadth $\left(M 71, \mathrm{rb}^{\prime}\right)^{*}$ & 37.5 & Coronion height (M70, crh) & 67.0 \\
\hline
\end{tabular}

NB: (S) indicates that symmetry of the mandible was assumed to estimate the measurement. (R) indicates measurement on the right side; otherwise, the left side was used. Asterisked measurements appear in the Penrose size and shape analysis (below). Where a measurement definition comes from Martin and Saller (1957:481-2), it is marked with M and the relevant number in their system. Alphanumerically tagged measurements are defined by Cleaver (1937); LM means the source is Larnach and Macintosh (1971:28-30); and other measurement definitions are from Jacob (1967: 61), and olivier et al. (1966) 
A combination of features such as this is more characteristic of southwest Pacific than East Asian mandibles. Eleven of the 12 'race discrimination' characters in Larnach and Macintosh (1971:30) are extant, and Lemdubu's score of 21/33 would fall within the range of overlap between Australian (20-32), Melanesian (20-32), and Iron Age to recent Indonesian mandibles (16.5-25), but above the recorded Northeast Asian range of 14-20 (Bulbeck 1981:Table 8-10). On the 11 characters used by the author (Bulbeck 1981:359) to distinguish Melanesian mandibles (range, 18-29) from their Indonesian counterparts (range, 14.5-23), the Lemdubu specimen scores 24. Lemdubu thus lies outside the recorded Indo-Malaysian range, even when we consider the reported, preceramic specimens from the Philippines (Tabon), Java (Wajak 2), and Malaysia (Gua Cha 1, Gua Peraling) whose range is 20.5-22 (Bulbeck 2004: Fig. 1). Males and females may be pooled in these comparisons as sexual dimorphism among Australasian mandibles seems to be insignificant here (Bulbeck 1981:359, 380).

For more detailed comparisons, we turn to Storm's (1995:235-6) description of nine anatomical features in Larnach and Macintosh's (1971) system based on casts of the WL3, Kow Swamp 1, and Kow Swamp 5 mandibles, and the originals of Leang Toge, Leang Momer E, Wajak 2, and Sampung (preceramic Java). Based on these data, the Lemdubu mandible most frequently matches Wajak 2 and Sampung in its morphology, followed by a reasonable similarity with the WL3 and Kow Swamp mandibles, and pronounced differences from Leang Toge and Leang Momer E (Table 12.14). Further, because I had earlier reported Wajak 2, based on a cast, it is possible to check comparability between Storm's observations and mine. Our observations disagree on four features, but all differences involve merely one step (Table 12.14), suggesting that differences between our observations may be considered definite when they are two steps removed. In that case, four of the nine features definitely differ between Lemdubu and Leang Momer E, and 3/9 definitely differ from Leang Toge, whereas the definite differences from Kow Swamp 5 (3/9), Wajak (2/9), Sampung (1/8), WL3 (1/8) and Kow Swamp $1(0 / 9)$ are less (Table 12.14). There seems little doubt that Lemdubu's mandibular morphology is particularly dissimilar from that of the Flores middle Holocene specimens.

Various traits not considered by Larnach and Macintosh (1971) may be noted on the Lemdubu mandible. The lower border of the posterior corpus does not display the pronounced convexity found on rocker jaws, which occur at rates of approximately 70-90\% across East Asia, Australia, and the Pacific (Pietrusewsky 1984:99, 104-6). The mental foramina are directed posteriorly and superiorly, as is the usual condition among Indonesian, Australian and other Pacific mandibles (Bulbeck 1981:370). The genial spines coalesce into a common median spine type G of de Villiers (1968:Fig. 55) — which is evidently a rare variant (cf. Bulbeck 1981:356, 373),

Table 12.14 Liang Lemdubu: mandibular anatomical comparisons

\begin{tabular}{lcccccccc}
\hline & & & & LEANG & LEANG & \\
FEATURE & LEMDUBU & WL3 & KS1 & KS5 & TOGE & MOMER & WAJAK 2 & SAMPUNG \\
\hline Trigone & marked & medium & medium & slight & medium & slight & medium" & - \\
Incurvature & medium & - & medium & medium & slight & medium & medium* & medium \\
Chin & $-v e$ & $-v e$ & neutral & - ve & $-v e$ & +ve & -ve & neutral \\
Planum alveolare & medium/large & slight & slight & medium/large & slight & slight & slight & medium/large \\
Mylohyoid & marked & marked & med. & slight & slight & medium & marked* & marked \\
Sulcus extramolaris & slight & marked & med. & slight & medium & slight & marked & medium \\
Prominence & marked & medium & marked & slight & slight & slight & marked & marked \\
Precoronoid & medium & medium & deep & shallow & medium & shallow & medium & shallow \\
triangulare & large & medium & large & medium & small & small & large & small \\
Agreement & $\mathrm{N} / \mathrm{A}$ & $3 / 8$ & $3 / 9$ & $4 / 9$ & $2 / 9$ & $2 / 9$ & $6 / 9$ & $4 / 8$ \\
\hline
\end{tabular}

NB: features are respectively mental trigone development, anterior mandibular incurvature, chin projection (-ve = negative, +ve = positive), planum alveolare decline, mylohyoid ridge development, sulcus extramolaris development, lateral prominence development, precoronoid fossa depth, and planum triangulare area. The last row shows the ratio of features shared between Lemdubu and the other mandible. KS = Kow Swamp. Comparative observations from Storm (1995:235-7); asterisked Wajak 2 observations show where his observations disagree with those made by myself (Bulbeck 1981:393), in all cases by one step 
and is associated with an absence of genial grooves in the Lemdubu case. Finally, there is no trace of a mylohyoid bridge (Lundy 1980), a feature that occurs at about 3-30\% rates among Pacific and Pacific Rim mandibles (Bulbeck 1981:375).

Five measurements, asterisked in Table 12.13, have been recorded in common on the Coobool Creek, Lemdubu and Leang Toge mandibles, as well as a useful spread of recent female populations in the region. Coobool Creek, Murray Valley, and Swanport data come from Brown (1989); Javanese data come from combining the measurements in Snell (1938:68-106) and Storm (1995:184-8); and my measurements on Papua New Guinea mandibles housed at the Australian Museum in Sydney are produced in Table 12.15. Storm (1995:184-5) gives the height and thickness of the Leang Toge corpus in the $\mathrm{M}_{1} / \mathrm{M}_{2}$ region, otherwise, Jacob's (1967:85) measurements are used.

The preferred statistic employed here is Penrose's (1954) size and shape statistic, as it usefully distinguishes between these two main components of overall metrical distance. The statistical formulae produce squared distances, so, to scale them back to Euclidean space, the square roots of the calculated distances are used here. Indeed, the square roots of the size differences obey the properties of one-dimensional Euclidean geometry, so size distinctions can be expressed as the square root of the distance from Papua New Guinea females, who proved to have the smallest mandibles. Thus the greater size of the Coobool Creek (1.91), Leang Toge (1.49), and Lemdubu (1.02) mandibles, compared to Papua New Guineans, is approximately two to four times the size difference of any recent sample - Murray Valley (0.58), Swanport (0.50), and Javanese (0.23) - compared to Papua New Guinea mandibles. Note also that the large size of the Leang Toge mandible contrasts with the situation in southeast Australia where, according to Brown's (1989:171-2; 1992:42) analysis, reduction in mandibular size to recent standards had been completed by the middle Holocene.

The shape distance square roots presented in Table 12.16 cluster (using the average-linkage algorithm) into the hierarchical dendrogram illustrated in Figure 12.11. The dendrogram is seriated in the way that ensures that, as far as possible, the greater the juxtaposition of any two samples, the smaller the shape distance between them, while samples spaced far apart from each other in the dendrogram differ markedly in their shape distances. Thus the smallest distances in Table 12.16 lie along the diagonal, and the greatest distances lie farthest from the diagonal. In a perfect seriation, each step away from the diagonal would encounter an equal or greater distance. This ideal is closely approached in Table 12.16 and, to be precise, its goodness of fit in comparison to a perfect seriation is $92.2 \%$ (for procedural details, see Bulbeck 1992:Appendix A; 1993; 1997; 2000b). So, all of the samples and specimens slot along a single main axis of variation with the Coobool Creek mandibles at one extreme, and the Lemdubu and Leang Toge mandibles at the other extreme (Fig. 12.11). In its shape, the Lemdubu mandible is very similar to the average Swanport mandible, but also quite similar to Papua New Guinea and Leang Toge.

Inspection of the original measurements reveals a major distinction between the Coobool Creek and Murray Valley mandibles, whose recorded average thickness at the $M_{1} / M_{2}$ region is small relative to their average height at the symphysis and the $M_{1} / M_{2}$ region, compared to the other samples and specimens where the opposite applies. This can be shown by constructing indices involving these measurements, where the relatively tall, slender shape of the Coobool Creek and Murray Valley mandibular corpora is quite clear (Table 12.17). However, no consistent pattern is observable when thickness at the $M_{1} / M_{2}$ region is compared to bigonial width or

Table 12.15 The author's measurements on female Papua New Guinea mandibles

\begin{tabular}{lrrrrr}
\hline & w2 & h1 & $M_{1} / M_{2}$ HEIGHT & $M_{1} / M_{2}$ THICKNESS & rb' \\
\hline No. observations & 25 & 21 & 25 & 24 & 25 \\
Mean & 89.46 & 28.33 & 24.80 & 14.21 & 32.68 \\
Standard deviation & 4.80 & 2.34 & 2.03 & 1.71 & 3.16 \\
\hline NB: acron
\end{tabular}


Table 12.16 Liang Lemdubu: seriated square roots of Penrose shape distances for five mandibular measurements (females)

\begin{tabular}{|c|c|c|c|c|c|c|c|}
\hline & $C C$ & MV & JAVANESE & PNG & SPT & LEMDUBU & L. TOGE \\
\hline Coobool Creek (cc) & - & 0.457 & 1.143 & 1.177 & 1.368 & 1.494 & 1.188 \\
\hline Murray Valley (MV) & & - & 0.751 & 0.770 & 0.975 & 1.180 & 0.961 \\
\hline Javanese & & & - & 0.464 & 0.767 & 0.976 & 1.099 \\
\hline Papua New Guinea (PNG) & & & & - & 0.345 & 0.617 & 0.701 \\
\hline Swanport (Spt) & & & & & - & 0.425 & 0.683 \\
\hline Lemdubu & & & & & & - & 0.758 \\
\hline Leang Toge (L. Toge) & & & & & & & - \\
\hline
\end{tabular}

Table 12.17 Liang Lemdubu: mandibular indices relating average measurements (females)

\begin{tabular}{lcccrrrr}
\hline & COOBOOL CREEK & MURRAY VALLEY & JAVA & PNG & SWAN-PORT & LEMDUBU & LEANG TOGE \\
\hline M1/M2 T:M1/M2 H & 47.2 & 45.5 & 55.6 & 57.3 & 58.8 & 56.6 & 58.8 \\
M1/M2 T:h1 & 39.8 & 43.4 & 51.7 & 50.2 & 50.2 & 51.7 & 46.7 \\
M1/M2 T:W2 & 14.3 & 15.3 & 16.9 & 15.9 & 15.8 & 15.1 & 14.7 \\
M1/M2 T: rb' $^{\prime}$ & 41.8 & 43.5 & 46.9 & 43.4 & 41.4 & 40.0 & 42.8 \\
W2:M1/M2 H + T & 224.2 & 203.8 & 211.0 & 229.5 & 234.5 & 239.8 & 252.4 \\
rb':M1/M2 H + T & 76.7 & 71.8 & 76.3 & 83.8 & 89.4 & 90.4 & 86.5 \\
rb':W2 & 34.2 & 35.3 & 36.1 & 36.5 & 38.1 & 37.7 & 34.3 \\
\hline
\end{tabular}

NB: indices are constructed from thickness (M1/M2 T) and height (M1/M2 H) of the corpus at the interval between the first and second molars, symphysis height (h1), bigonial width (w2) and minimum ramus breadth (rb')

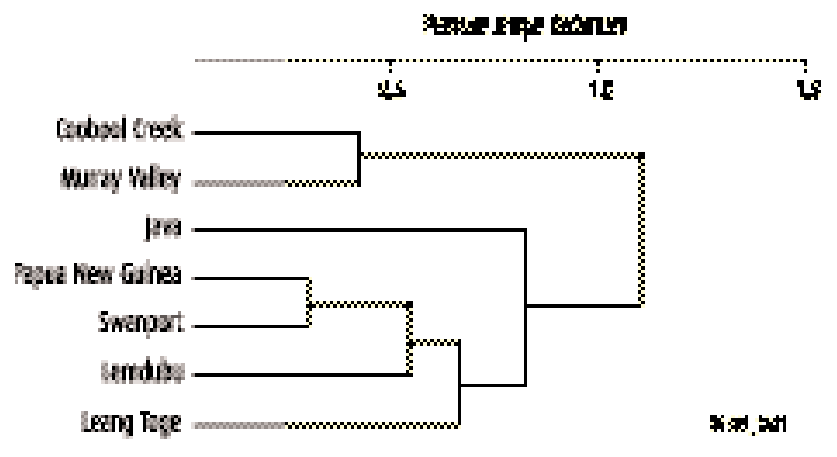

Figure 12.11 Seriated average-linkage dendrogram of female mandible shape distances (bigonial width, symphysis height, ramus breadth, corpus diameters at $M_{1} / M_{2}$ ). Goodness of fit $92.2 \%$ minimum ramus breadth; instead, the latter two measurements appear to be specifically large as a common feature of the Swanport, Lemdubu and Leang Toge mandibles. This can be shown by expressing these two measurements as an index relative to the sum of the height and the thickness at the $M_{1} / M_{2}$ region, yielding highest values for Swanport, Lemdubu and Leang Toge (Table 12.17). On the other hand, Leang Toge has a relatively small minimum ramus breadth compared to bigonial width, a feature it specifically shares with the Coobool Creek and Murray
able 12.17). This may explain why Leang Valley mandibles, as reflected in a small $\mathrm{rb}^{\prime}: \mathrm{w}_{2}$ index (Table 12.17). This may explain why Leang
Toge has slightly smaller shape distances from Coobool Creek and Murray Valley than Swanport and Lemdubu do (Table 12.16), a detail which is not reflected in the seriation, and which would indeed explain most of $7.8 \%$ discrepancy (100\% minus $92.2 \%$ ) from a perfectly seriated order.

To summarize, the Lemdubu mandible is tolerably close to Leang Toge in both size and shape, but its shape is particularly reminiscent of Swanport (Australian) mandibles, even if it is much larger than the Swanport average. It differs considerably from Coobool Creek (and Murray Valley) mandibles in its squatter corpus and relatively broad ramus and bigonial width. These metrical comparisons differ somewhat from the analysis using anatomical features where, as noted above, Lemdubu differs sharply from Leang Toge (and Leang Momer E), and instead shows an overall resemblance to recent Melanesians, Australian Aborigines both past and present, and preceramic mandibles from Java. 


\section{Postcranial Description}

The Lemdubu individual (Fig. 12.1) shows a tall, linear build, and long distal members compared to proximal limb bone lengths. Muscular development would appear to have been moderate to strong, to judge by the related osseous features. The morphology of the limb bones is slender, apart from the femora, which show a masculine degree of thickness ('robustness') that is presumably related to the individual's considerable stature (around $166 \mathrm{~cm}$ ) when alive. In contrast, the Leang Toge individual was evidently less muscular, much shorter in stature, and less linear in build. A notable feature of Lemdubu Woman is her thick cortical bone on the humerus and femur, to a degree usually found among Neandertals and other archaic hominins, and which is not shared by the Kow Swamp skeletons (at least, on the femur). Comparisons between Lemdubu Woman and the Lake Nitchie male, a huge individual of around $187.5 \mathrm{~cm}$ stature who lived approximately 7000 years ago in western New South Wales (Macintosh 1971), demonstrate the less linear build of the latter skeleton, as detailed below. Lemdubu Woman's more linear build, which also holds true in relation to recent southeast Australian Aborigines, would be an expected concomitant of her tropical lowland habitat, even during the Last Glacial Maximum.

\section{Postcranial axial skeleton}

Reconstruction of the vertebral column was based on the discs' anatomical features and measurements, and my best attempts to articulate the extant cranial and caudal disc surfaces (Fig. 12.12). Very rarely was it possible to relate any of the discs to the other vertebral fragments. The axis appeared to be represented only by its right superior articular surface and pedicle, the atlas by its left and right superior articular facets, the sixth and seventh cervical vertebrae by a single nondescript fragment, and the fifth and sixth thoracic vertebral discs by small fragments. Otherwise measurements could be made on all of the discs, including the first sacral disc, which was anchored to the second sacral disc but not fused to it. Such 'lumbarisation' of the S1 segment more commonly affects females than males, at rates of up to about $10 \%$ of women, according to Aufderheide and Rodrígues-Martín (1998:66).

Pathological pitting, with a 'punched out' appearance to the larger holes, was consistently noted on the Lemdubu vertebral discs except the sacral, third thoracic and upper cervical discs (Fig. 12.12). It took the form of a single puncture at the middle level of the disc on the sixth (or seventh) cervical, the first thoracic, and the second thoracic discs. This pitting affected the dorsal surface in the first two cases and the ventral surface in the third case. The fourth thoracic disc appears internally eroded, while the sixth thoracic disc has a nine millimetre deep hole on its right side. The seventh to ninth thoracic discs are pitted with 10 to 14 small holes on their left side (right side not well enough preserved for definitive observations), while the 10th thoracic disc is bilaterally pitted with 10 holes of various sizes. The 11th and 12th thoracic discs have two main punctures bilaterally expressed on the ventral face, accompanied by approximately a dozen smaller holes on both discs. The first, second and fourth lumbar discs could show a similar expression, but either the left or the right side is poorly preserved, even while the better preserved side exhibits a main

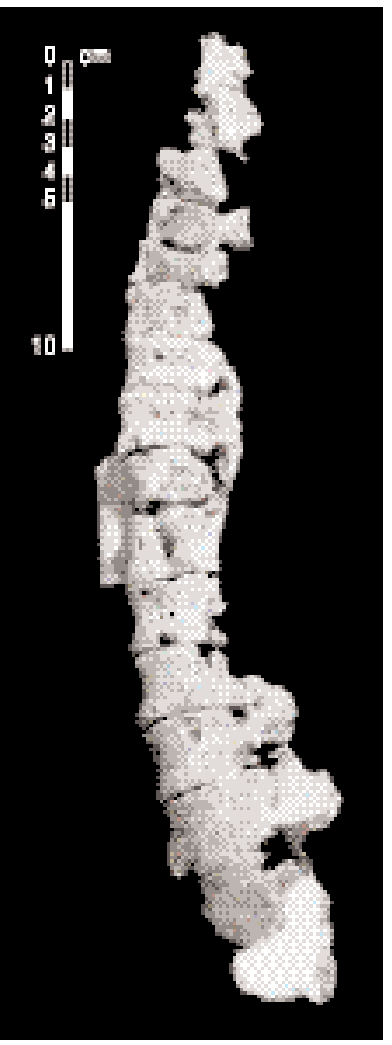

Figure 12.12 Liang Lemdubu: left lateral view of the reconstructed vertebral column of Lemdubu Woman hole. Large bilateral holes can be observed on the fifth lumbar disc, 
but the third lumbar disc is much less affected, with none of the holes larger than two millimetres in diameter.

The bone of the discs sometimes appears eroded from within, as is characteristic of multiple myelomic lesions (Rothschild et al. 1998). However, multiple myeloma is so rare among people aged less than 40 years that, when diagnosed for a younger person, it has probably been confused with a metastatic carcinoma (Aufderheide and Rodrígues-Martín 1998:351-3). Further, even though the vertebrae would be the prime site of myelomic lesions, they should still be widely distributed around the skeleton. This is not the case with Lemdubu Woman, where comparable lesions were noted at only two other parts of the skeleton, to wit, the medio-dorsal epiphysis of the right tibia, with a $22 \mathrm{~mm}$ deep hole of $8-8.5 \mathrm{~mm}$ diameter, and the right clavicle, with an oval pit $11.5 \mathrm{~mm}$ long by $4.5 \mathrm{~mm}$ wide and five millimetres deep on the cranial surface near the rhomboid impression. The focus of the lesions on the vertebral column does however rule out myelocytic leukaemia as the cause, when most of the skeleton should have been affected, as well as syphilis, yaws or trepanamotosis, which characteristically affect the cranium and the tibiae moreso than the vertebrae (cf. Rothschild et al. 1998). Further, Aufderheide and Rodrígues-Martín (1998:388) note that $30-50 \%$ of breast cancers may metastasise as lesions to the vertebrae, and other cancers may do so at lower frequencies. Accordingly, a metastatic cancerous lesion at an early stage of development is the most likely diagnosis for Lemdubu Woman's palaeopathological condition.

Aufderheide and Rodrígues-Martín (1998:388) further note that metastases commonly lead to vertebral collapse, and this may be related to the unusually small dorsal heights of Lemdubu Woman's vertebral discs. These heights are usually less than the ventral heights on the same disc (Table 12.18), in contrast to recent South Australian Aborigines whose dorsal disc heights usually exceed the ventral heights except on the lowest two lumbar vertebrae (Tulsi 1972). Impressionistically speaking, any vertebral collapse would seem to have had only minor effects on the Lemdubu disc heights, especially on their ventral aspect (Fig. 12.12). So the similarity between Lemdubu Woman and South Australian females in their summed ventral height of those discs that can be compared - 263mm for Lemdubu, compared to the female Australian average of 260.08mm (Tulsi 1972) - can be taken to reflect a similar length of the vertebral column regardless of any effects of pathology. By the same token, Lemdubu Woman would have had a short column compared to recent Japanese and American white females, because Tulsi (1972) found the Australian ventral disc heights to be consistently shorter, on average, than those of Japanese and American whites of the same sex.

The Lemdubu and Leang Toge vertebrae can be compared on 12 measurements, as asterisked in Table 12.18. The only systematic difference is the consistently greater dorsal disc heights of Leang Toge, which may however reflect pathological shortening of Lemdubu Woman's dorsal disc heights. On the other hand, the Leang Toge disc heights also exceed the South Australian averages, except for the dorsal height on the first lumbar vertebra (cf. Tulsi 1972:131). These comparisons may suggest that the much shorter long bones of Leang Toge compared to Lemdubu, as discussed below, were to some degree compensated by Leang Toge's longer vertebral column. It may also be noted that the summed height of the ventral discs of the Lake Nitchie burial is around 34\% greater than the South Australian male average, and the pattern is consistent on every vertebral disc (Macintosh 1971:51; cf. Tulsi 1972:131, 133), showing that Lake Nitchie did not have a short vertebral column, compared to its stature, by recent South Australian standards.

Three joining fragments of the sternum, including a complete manubrium were identified. Length of the manubrium is $41.5 \mathrm{~mm}$, its maximum and minimum breadths are $48 \mathrm{~mm}$ and $21 \mathrm{~mm}$ respectively, and its maximum thickness is $9.5 \mathrm{~mm}$ (M1, 4, 6 and 7, according to Martin and Saller 1957:571). These dimensions correspond to a fairly small sternum, in accord with the individual's sex. The potential area to see if there is a sternal foramen (Brothwell 1981:97) is not preserved. 
Table 12.18 Liang Lemdubu: measurements and estimates of the vertebral discs (to nearest $0.5 \mathrm{~mm}$ )

\begin{tabular}{|c|c|c|c|c|c|c|}
\hline \multirow[t]{2}{*}{ VERTEBRAL DISC } & \multicolumn{2}{|c|}{ HEIGHTS (M1-2) } & \multicolumn{2}{|c|}{ CRANIAL DIAMETERS (M4-5) } & \multicolumn{2}{|c|}{ CAUDAL DIAMETERS (M7-8) } \\
\hline & VENTRAL & DORSAL & SAGITTAL & TRANSVERSE & SAGITTAL & TRANSVERSE \\
\hline 3rd cervical & 9.0 & 9.5 & 11.5 & $\sim 20.0$ & 13.0 & 16.5 \\
\hline 4th cervical & 12.0 & 11.0 & 13.0 & 21.0 & 12.0 & 17.0 \\
\hline 5th cervical & 10.0 & 11.0 & 13.0 & 24.5 & $\sim 14.0$ & 25.0 \\
\hline 1st thoracic & 14.0 & 13.0 & 13.0 & 26.5 & 14.0 & 26.5 \\
\hline 2nd thoracic & $\sim 14.0$ & - & - & $\sim 25.5$ & - & $\sim 26.5$ \\
\hline 3rd thoracic & 14.0 & 15.0 & 13.0 & 23.0 & 13.0 & 23.0 \\
\hline 4th thoracic & - & 15.0 & - & $\sim 25.0$ & - & - \\
\hline 7th thoracic & - & - & - & - & $\sim 17.0$ & $\sim 26.0$ \\
\hline 8th thoracic & 16.0 & $\sim 15.5$ & $\sim 21.5$ & $\sim 29.0$ & $\sim 21.0$ & $\sim 32.0$ \\
\hline 9th thoracic & 17.0 & - & - & - & - & - \\
\hline 10th thoracic & 18.5 & 18.0 & 26.0 & $\sim 30.0$ & 28.0 & $\sim 32.0$ \\
\hline 11th thoracic & 21.0 & 18.0 & 23.0 & 26.0 & 22.0 & 28.0 \\
\hline 12th thoracic & 21.5 & $" 22.0$ & 22.5 & "27.5 & $\sim 23.5$ & 32.0 \\
\hline 1st lumbar & - & $* 21.0$ & - & $\sim 35.0$ & - & - \\
\hline 2nd lumbar & $\sim 24.0$ & $* 21.0$ & $\sim 26.0$ & $\sim 33.0$ & $\sim 29.0$ & $\sim 33.0$ \\
\hline 3rd lumbar & 24.0 & $" 23.0$ & 28.0 & $\sim 36.0$ & 32.0 & $\sim 34.0$ \\
\hline 4th lumbar & $" 23.0$ & $* 21.0$ & $\sim 31.0$ & $\approx \sim 40.0$ & "34.0 & $" 45.0$ \\
\hline 5th lumbar & 25.0 & $* 21.0$ & 32.0 & 44.5 & 29.0 & $\sim 44.0$ \\
\hline 1st sacral & 27.0 & $\sim 23.0$ & 27.0 & 44.5 & 24.0 & 29.0 \\
\hline
\end{tabular}

NB: measurements in bold exceed Tulsi's (1972) female Australian Aboriginal averages; asterisked measurements are those that can be compared with Leang Toge (Jacob 1967:92); italicized measurements indicate that Leang Toge has the larger measurements

\section{Shoulder girdle}

The Leang Toge remains do not include the clavicle (Jacob 1967:79), so we shall restrict comparisons to Australians. The Lemdubu measurements (Table 12.19) always fall within the female Australian range (Ray 1959:219), although the minimum width is located much farther from the inner end of the clavicle than is the usual case for Aborigines, and the inner segment length slightly exceeds the corresponding Australian average (a shape difference related to the greater torsion of the Lemdubu clavicle at the outer angle). In other respects, Lemdubu lies slightly below the recorded Australian average (Table 12.19). Based on the estimated, maximum humerus length of $313 \mathrm{~mm}$ for Lemdubu Woman, and her maximum clavicle length of about $119 \mathrm{~mm}$, her claviculo-humeral index would be approximately 38.0. This value would fall towards the bottom of the recent Australian range, even though Australian Aborigines exceed most other recent

Table 12.19 Liang Lembudu: right clavicle measurements (Lem.) and female Australian (Aus.) means

\begin{tabular}{lrrlrr}
\hline MEASUREMENT & LEM. & AUS. & MEASUREMENT & LEM. & AUS. \\
\hline Maximum length & $\geq 119$ & 123.5 & Sternal-acromial distance & $\geq 116$ & 120.6 \\
Inner angle & $\sim 150$ & 149.3 & Outer angle & $\sim 147$ & 140.8 \\
Inner segment length & 41 & 36.1 & Middle segment length & 54 & 63.7 \\
Outer segment length & 23 & 26.6 & Mid-point circumference & 31 & 32.1 \\
Inner end width & 17 & 18.6 & Inner angle width & 10.5 & 10.9 \\
Minimum width & 9 & 9.8 & Inner end-minimum width distance & 79 & 30.9 \\
Width at conoid & 11 & 14.0 & Minimum height at outer end & 7.5 & 7.6 \\
Height at conoid & 8 & 9.9 & Thickness index & $\leq 26.1$ & 26.0 \\
Mid-point height & 8 & 10.1 & Mid-point width (M4) & 10 & - \\
\hline
\end{tabular}

NB: all measurements in $\mathrm{mm}$ except the angles (in degrees). Thickness index is $100 \mathrm{x}$ mid-point circumference/maximum length. Left clavicle measurements also available for the mid-point circumference $(30 \mathrm{~mm})$, width and height at conoid tubercle (10.5 and $7.5 \mathrm{~mm}$ respectively), and midpoint width and height (10.5 and $7.5 \mathrm{~mm}$ respectively) 
populations in the shortness of their clavicle compared to their humerus length, as one aspect of their linear build (Ray 1959:221). The very low claviculo-humeral index of Lemdubu Woman highlights her linear build.

The pathological hole near the rhomboid impression on the right clavicle makes it hard to define the development of anatomical features in this area, but fortunately the left Lemdubu clavicle preserves these features well (Table 12.20). In addition to the traits itemised in Table 12.20, no accessory perforations were noted, here following the usual Australian condition (Ray 1959:222); the impression for the first rib is a shallow furrow, and the trapezoid ligament has left a shallow oval impression, so its apparently large size may reflect differences in definitions between Ray's and mine. To be sure, Ray's categories are not sufficiently well defined to guarantee accurate comparisons, so the comparisons in Table 12.20 serve mainly to confirm the visual impression that the Lemdubu clavicles are generally rather gracile, in accord with the skeleton's female status (cf. Ray 1959:225). In contrast, the Lake Nitchie clavicles have more rugged muscular markings, as per their male status, and the length measurements lie near the top of the recent Australian range, in accord with the individual's great size (Macintosh 1971:52). Similarly, the clavicle from the Lake Tandou male, buried about 15,000 years ago near Lake Nitchie, has a diameter close to the top of the recent Australian range (Freedman and Lofgren 1983; Ray 1959:219).

The Lemdubu scapulae are poorly preserved, with only the lateral border, glenoid cavity, acromion and coracoid process present to any degree. The dimensions are rather large compared to those of other female skeletons in the vicinity. Coraco-acromial breadth and glenoid fossa diameters fall within the range of overlap between recent male and female Australians (van Dongen 1963:482-3; see also Table 12.21, this volume), while the glenoid fossa diameters and acromial dimensions are larger than those of Leang Toge (Table 12.21). Yet her glenoid fossa diameters measure 6-8mm less than those of the robustly built Lake Nitchie male (cf. Macintosh 1971:52). Two further measurements may be taken on the right scapula of Lemdubu Woman: maximum length of the coracoid process (M11), which measures $38 \mathrm{~mm}$; and depth of the glenoid fossa (M14), which measures approximately $4.5 \mathrm{~mm}$.

These Lemdubu scapulae show complete absence of the following semi-discrete traits illustrated by Brothwell (1981:97, 99): suprascapular foramen, rectangular acromion, acromial articular facet, and glenoid extensions. Bilaterally, there is no trace of a suprascapular notch, as also

Table 12.20 Liang Lembudu: percentages of female Australians (\% Aus.) sharing the Lemdubu clavicular non-metric trait expression (based on Ray 1959:222-5)

\begin{tabular}{lrlr}
\hline LEMDUBU WOMAN'S CONDITION & \% AUS. & LEMDUBU WOMAN'S CONDITION & \% AUS. \\
\hline Small rhomboid impression (L) & 24 & Small impression for first rib (L) & 34 \\
Nutrient foramen a single large pit (L) & 42 & Nutrient foramen not patent (R) & 4 \\
Irregular inner end shape (R) & 24 & Absent sternocleidomastoid impression (L, R) & 29 \\
Small pectoralis major impression (R) & 37 & Absent deltoid impression (R) & 1 \\
Medium subclavian groove (L) & 30 & Small subclavian groove (R) & 42 \\
Large conoid tubercle (R) & 18 & Medium trapezoid ligament (R) & 35 \\
\hline
\end{tabular}

Table 12.21 Liang Lembudu: scapula measurements $(\mathrm{mm})$ compared to Leang Toge and recent Australians

\begin{tabular}{lrrrr}
\hline MEASUREMENT & LEMDUBU & L. TOGE & AUSTRALIAN + & AUSTRALIAN $\sigma^{\overline{7}}$ \\
\hline Coraco-acromial breadth & $67(\mathrm{R})$ & - & $60.3 \pm 3.2$ & $68.8 \pm 5.1$ \\
Vertical glenoid diameter (M12) & $34(\mathrm{R}), \sim 33(\mathrm{~L})$ & $29(\mathrm{R}), 28(\mathrm{~L})$ & $30.9 \pm 1.8$ & $35.3 \pm 2.3$ \\
Transverse glenoid diameter (M13) & $22(\mathrm{~L}, \mathrm{R})$ & $22(\mathrm{R}), 21(\mathrm{~L})$ & $21.7 \pm 1.3$ & $24.8 \pm 1.8$ \\
Acromial breadth (M9) & $\geq 39(\mathrm{R})$ & $36.5(\mathrm{R})$ & - & - \\
Acromial length (M10) & $51(\mathrm{R})$ & $41(\mathrm{R})$ & - & - \\
\hline
\end{tabular}

NB: Leang Toge measurements from Jacob (1967:85). Recent Australian measurements from van Dongen (1963:479). Measurements defined by Martin and Saller (1957:530-1) are indicated with an M 
noted on approximately fifty percent of Australian Aborigines (van Dongen 1963:477) and, reading between the lines, on Leang Toge (Jacob 1967:85). The axillary borders are strongly developed and show extensive 'dorsal inclination', a feature more common among male than female Australians (van Dongen 1963:477) and also displayed by Leang Toge (Jacob 1967:85). The circumflex groove of Lemdubu Woman is slight on the left scapula and large on the right; presence of this groove occurs on less than half the recorded Australian scapulae, but is observed on Leang Toge (Jacob 1967:85; van Dongen 1963:478). The bilaterally piriform shape of the Lemdubu glenoid cavity is the most common condition among all people, including Australians and Leang Toge (Jacob 1967:85; van Dongen 1963:478). Further similarities with the Leang Toge scapulae include the triangular shape of the acromial extremities, well-developed markings where the teres minor muscles inserted, and general rugosity by usual female standards.

\section{The arms}

Only the left Lemdubu humerus is considered here because it is much better preserved than the right antimere. Its maximum length is estimated from its measured lengths of $33 \mathrm{~mm}$ for segment 1 (Steele 1970; Steele and McKern 1969), 54mm and 192mm respectively for segments 2 and 3 (Steele and McKern 1969), and 246mm for segment 2 (Steele 1970). These measurements indicate a maximum length of around $313 \mathrm{~mm}$ (Table 12.22) whether we employ the regression formulae for Mesoamerican females (Steele and McKern 1969 - 311.3 $\pm 3.7 \mathrm{~mm}$ ), American Whites $(312.6 \pm 3.0 \mathrm{~mm}$ ), or Afro-Americans $(313.2 \pm 3.0 \mathrm{~mm}$ ) (Steele 1970). The Lemdubu value lies slightly above the maximum humerus lengths of 305mm to 310mm estimated by Webb (1989:47) for female humeri from the Willandra Lakes.

Other measurements may be taken directly and are compared with Leang Toge and recent Australian females in Table 12.22. These measurements show little in the way of noteworthy differences. For instance, platybrachy, or a flattish humerus mid-shaft with a diaphyseal index less than 76.5 (Jacob 1967:86), characterizes all of the comparisons. Being longer than the average female Australian humerus, and much longer than the Leang Toge humerus, the Lemdubu humerus has a lower calibre index than either of the latter (Table 12.22), further demonstration of its female status (cf. van Dongen 1963:472-3). In contrast, the calibre index of the Willandra Lake humeri is consistently estimated to be larger, between 17.5 and 22.8, and their mid-shaft shape rounder, with a diaphyseal index greater than 76.5 in 17 of the 18 recorded cases (Webb 1989:47). Relatively round mid-shafts are also registered for the Lake Tandou, Lake Nitchie and Cossack humerus diaphyseal indices, which all lie between 76.2 and 84.0 (Freedman and Lofgren 1979:291; Freedman and Lofgren 1983:103; Macintosh 1971:52).

Table 12.22 Liang Lemdubu: left humerus measurements (mm) compared to Leang Toge (Jacob 1967:86) and Australian females (van Dongen 1963:471)

\begin{tabular}{lrrr}
\hline MEASUREMENT & LEMDUBU & LEANG TOGE & AUSTRALIANS \\
\hline Maximum length (M1) & $\sim 313$ & $273(\mathrm{R})$ & $302.4 \pm 14.1$ \\
Upper epiphysis breadth (M3) & 41 & $\sim 42(\mathrm{R})$ & - \\
Humerus head circumference (M8) & 113 & - & $111.5 \pm 5.4$ \\
Humerus head transverse diameter (M9) & $\sim 34.5$ & $32(\mathrm{R})$ & $34.2 \pm 1.9$ \\
Humerus head vertical diameter (M10) & 34 & $38(\mathrm{R})$ & $36.3 \pm 2.3$ \\
Major diameter at shaft mid-point (M5) & 16.5 & $18(\mathrm{~L}), 17(\mathrm{R})$ & $17.3 \pm 1.8$ \\
Minor diameter at shaft mid-point (M6) & 12 & $13(\mathrm{~L}, \mathrm{R})$ & $12.9 \pm 1.5$ \\
Diaphyseal index (100xM6/M5) & 72.7 & $72.2(\mathrm{~L}), 76.5(\mathrm{R})$ & $75.3 \pm 5.8$ \\
Mid-shaft circumference (M8) & 50 & $48(\mathrm{~L}), 49(\mathrm{R})$ & $48.5 \pm 4.4$ \\
Calibre Index (100xM8/M1) & $\sim 16.0$ & 17.9 & $16.1 \pm 1.4$ \\
\hline
\end{tabular}

NB: for mid-shaft circumference, the exact measurements provided are sub-deltoid circumference for Leang Toge and minimum circumference for Australians. M: Martin and Saller (1957:532-3) 
In accord with its slender shape, muscular relief on the Lemdubu humerus is modest. Examples include its very weak (almost imperceptible) deltoid tuberosity, moderately developed pectoralis major crista, and the broad and shallow intertubercular groove. The Lemdubu and Leang Toge humeri are specifically similar in the morphology of their intertubercular groove, and the ovoid shape of their diaphysis in cross-section (cf. Jacob 1967:86).

The Lemdubu radii are represented by the head and proximal shaft on the right, and the distal shaft and epiphysis on the left. Both radii are very long and slender. As the medio-distal shaft is present on both sides, we may appose the two extant segments and infer an approximate length of $270 \mathrm{~mm}$ (Table 12.23). This value would lie beyond the recent female Australian range and above the recent male Australian average (Rao 1966:265), and would approximate the maximum length of 276mm measured on the Lake Nitchie right radius (Macintosh 1971:52). The remarkably long Lemdubu radius is also apparent when related to the circumference of the shaft (as reflected in a low calibre index) and to maximum humerus length. Note that, in both these respects, Leang Toge provides a closer match to Lemdubu Woman than recent Australians do, notwithstanding the much greater length of the Lemdubu radius compared to Leang Toge's (Table 12.23).

Jacob (1967:87) remarks on the gracile morphology of the Leang Toge radii, but this would be less true of the Lemdubu radii. The right side shows a very strongly developed interosseous fossa, a dull radial tuberosity of moderate size, and a long, well-developed groove for the abductor pollicis longus muscle. Asymmetric development is apparent with the groove for the extensor pollicis brevis muscle (moderately developed on the left, but barely noticeable on the right), and with the inferior groove for the flexor pollicis longus muscle (well-developed on the left but not on the right). The distal radius is gracile as shown by its shallow fossa for the attachment of the pronator quadratus muscle, the undetectable attachment area for the pronator teres muscle, and the small inferior epiphysis breadth of 30mm (M5[6]). Additional measurements not included in Table 12.23 for the right radius, according to Martin and Saller's (1957:536-7) definitions, are: transverse and sagittal diameters of the head, $19.5 \mathrm{~mm}$ and $19 \mathrm{~mm}$ respectively (M4[1] and M5[1]); head circumference, $62 \mathrm{~mm}$ (M5[3]); neck sagittal diameter, $10.5 \mathrm{~mm}$ (M5[2]); neck circumference, 35mm (M5[4]); and mid-shaft circumference, 36mm (M5[5]).

The Lemdubu ulnae consist of the proximal epiphysis and shaft on the right side, as well as a portion of the right distal shaft, and a couple of fragments from the left proximal shaft. The extant shaft is thick relative to female Australian Aborigines or Leang Toge, whereas the upper epiphysis measurements compare well with female Australian averages but usually exceed those measured on Leang Toge (Table 12.24). An exception is that Lemdubu does not share the marked olecranon depth of Leang Toge, which Jacob (1967:87) observes to be a rare feature. The right Lemdubu ulna presents very sharp supinator and interosseous crests, a robust coronoid process, strong development of the furrow for the extensor pollicis longus muscle and the ulna's anterior border, a well-defined if shallow area for the insertion of the anconeus muscle, and a slightly developed furrow for the extensor indicis muscle. Overall, the Lemdubu ulna appears rugged relative to its radius. Other available measurements on the right ulna, following Martin and Saller's (1957:540-1) definitions, are as follows: height of the proximal facet and humerus facet (M5[1] and M5[2]), $34 \mathrm{~mm}$ and 22mm respectively; upper ulna breadth (M6[1]), 28mm; anterior and posterior breadth of the radial notch (M9 and M10), $11.5 \mathrm{~mm}$ and $8.5 \mathrm{~mm}$ respectively; and dorso-volar and transverse diameters of the shaft (M11 and M12), 13mm and 11mm respectively.

\section{The innominate bones}

The demonstrably female status of the Lemdubu (and Leang Toge) innominate bones was noted above. The Lemdubu innominates could be considered as being of typically Australian shape but of above average size (Table 12.2). This description could equally apply to the Lake Nitchie innominates, whose pubic length, ischial length and greatest depth of the sciatic notch lie close to 
the recent male Australian maxima, while its sciatic notch greatest width lies close to the recent male Australian mean (cf. Davivongs 1963a:448 and Macintosh 1971:51). Leang Toge shows a slightly greater iliac breadth than Lemdubu and consequently a much larger coxal index, but its other measurements as indicated in Table 12.2 are 1-10 $\mathrm{mm}$ less than their Lemdubu counterparts. Two further measurements of the innominate can be compared (see Jacob 1967:89) and these indicate considerable differences in the shape of the iliae. Specifically, Lemdubu's minimum iliac breadths $(66 \mathrm{~mm}$ left, $68 \mathrm{~mm}$ right) are much larger than Leang Toge's measurement of $57 \mathrm{~mm}$ (M13), while the Lemdubu iliac height (112 mm left) is considerably less than the Leang Toge values of $121 \mathrm{~mm}$ and $122 \mathrm{~mm}$ (M9). Some further measurements, as defined by Martin and Saller (1957:550-9) and / or Arsuaga and Carretero (1994), are listed in Table 12.25.

The Lemdubu innominates display intermediate robustness (Fig. 12.4). The iliac crest is moderately developed, with a well-developed tubercle on both sides, a large anterior superior iliac spine (at least, on the left), and a sharp if small anterior inferior iliac spine. The iliac fossae are

Table 12.23 Liang Lemdubu: radius measurements (mm) compared to Leang Toge (Jacob 1967:88) and Australian females (Ra0 1966:265-6)

\begin{tabular}{lrrr}
\hline MEASUREMENT & LEMDUBU & LEANG TOGE & AUSTRALIANS \\
\hline Maximum length (M1) & $\sim 270$ & $223(\mathrm{~L})$ & $235.8 \pm 12.1$ \\
Radio-humeral index (maximum lengths) & $\sim 86.3$ & 81.7 & $\sim 77.8$ \\
Least circumference, distal half (M3) & $35(\mathrm{R})$ & $30(\mathrm{~L}, \mathrm{R})$ & $35.0 \pm 3.0$ \\
Calibre Index (100xM3/M1) & $\sim 13.0$ & 13.5 & $15.5 \pm 1.3$ \\
Shaft transverse diameter (M4) & $12.5(\mathrm{R})$ & - & $12.8 \pm 1.5$ \\
Mid-shaft transverse diameter (M4a) & $12(\mathrm{R})$ & $10(\mathrm{~L}), 11(\mathrm{R})$ & - \\
Shaft sagittal diameter (M5) & $10(\mathrm{R})$ & - & $10.1 \pm 0.9$ \\
Mid-shaft sagittal diameter (M5a) & $10(\mathrm{R})$ & $9(\mathrm{~L}, \mathrm{R})$ & - \\
Diaphyseal index (100xM5/M4) & $80.0(\mathrm{R})$ & $75.0(\mathrm{~L})$ & $78.8 \pm 7.7$ \\
Neck transverse diameter (M4(2)) & $10(\mathrm{R})$ & $10(\mathrm{~L})$ & - \\
Collo-diaphyseal angle (M7) & $160^{\circ}(\mathrm{R})$ & $162^{\circ}(\mathrm{L})$ & $164^{\circ} \pm 2.9$ \\
\hline
\end{tabular}

NB: as Rao (1966:266) used physiological lengths in deriving the Australian radio-humeral index, the Australian value in Table 12.23 is estimated from the average maximum lengths for the radius and humerus (cf. Table 12.22). M: Martin and Saller (1957:535-8)

Table 12.24 Liang Lemdubu: right ulna measurements (mm) compared to Leang Toge (Jacob 1967:88) and Australian females (Rao 1966:267-8)

\begin{tabular}{lrrr}
\hline MEASUREMENT & LEMDUBU & LEANG TOGE & AUSTRALIANS \\
\hline Minimum circumference (M3) & $\sim 34$ & $30(\mathrm{~L}), 31(\mathrm{R})$ & $30.3 \pm 2.4$ \\
Height of olecranon cap (M5) & 4 & $3(\mathrm{~L}, \mathrm{R})$ & $4.3 \pm 1.1$ \\
Olecranon breadth (M6) & 21 & $19(\mathrm{~L}), 18.5(\mathrm{R})$ & $21.3 \pm 1.7$ \\
Olecranon depth (M7) & 15 & $21(\mathrm{~L}, \mathrm{R})$ & $16.7 \pm 1.1$ \\
Olecranon-coronoid distance (M7(1)) & 24.5 & $23(\mathrm{~L})$ & - \\
Upper transverse diameter (M13) & 20 & $16.5(\mathrm{~L}), 16(\mathrm{R})$ & - \\
Upper sagittal diameter (M14) & 17.5 & $14.5(\mathrm{~L}), 15(\mathrm{R})$ & - \\
\hline
\end{tabular}

NB: M: Martin and Saller (1957:539-41)

Table 12.25 Liang Lemdubu: further measurements $(\mathrm{mm})$ of the right innominate

\begin{tabular}{ccccccccc}
\hline MARTIN & A\&C & VALUE & MARTIN & A\&C & VALUE & MARTIN & A \& $~$ & VALUE \\
\hline 3 & 22 & $\sim 145$ & 4 & 1 & $\sim 108$ & 10 & - & 98 \\
14 & - & $\sim 94$ & - & 16 & 46 & 21 & - & $\sim 55$ \\
28 & - & 94 & 29 & - & $\sim 106$ & 30 & - & 107 \\
\hline
\end{tabular}

NB: Martin's measurement No.10 (Martin \& Saller 1957:556) is 102mm on the left side, and A \& C measurement No.16 (Arsuaga and Carretero 1994) is $46.5 \mathrm{~mm}$ on the left side 
rather deep and the bone here often appears paper thin, as thin as $0.3 \mathrm{~mm}$ in places. The arcuate line is weakly expressed on the right side and very weak on the left. The ischial tuberosity is a solid, swollen structure bilaterally. The gluteal lines are not visible on either side, nor is there an acetabular crease, but the arterial impressions are visible on the right side.

\section{The legs}

The extant Lemdubu femora convey the visual impression of impressive length, as confirmed by my attempt to estimate their maximum length. Segment 3 of Steele and McKern (1969) and Steele (1970) measures approximately $77 \mathrm{~mm}$ on the right member, which would lead to length estimates of the complete bone of $444.9 \pm 16.7 \mathrm{~mm}$ (based on the female Mesoamerican formula in Steele and McKern 1969), $464.1 \pm 26.0 \mathrm{~mm}$ and $476.5 \pm 20.7 \mathrm{~mm}$ (based, respectively, on the female American White and Afro-American formulae in Steele 1970). This range of estimates essentially matches the maximum lengths of $444-470 \mathrm{~mm}$ that lie more than one standard deviation above the average as measured on recent female Australian femora (Davivongs 1963b:459). Thus, the length of the Lemdubu femora would have lain at the top of the recent female Australian range. Similarly, Webb (1989:49) provides maximum length estimates of 435-463mm for the female femora from the Willandra Lakes, while the Lake Nitchie femoral lengths lie more than two standard deviations above the recent Australian average (cf. Davivongs 1963b:459 and Macintosh 1971:52). The Lemdubu femora would certainly have been much longer than is the case with Leang Toge whose left femur has a maximum length of merely 380mm (Jacob 1967:90).

Other measurements and indices available on the Lemdubu femora include several that fall beyond the recent female Australian range and indeed appear hyper-masculine, including pilastric index (reflecting the strongly developed linea aspera), popliteal index, and transverse condylar breadth (Table 12.26). However, Lemdubu falls among good company: both male and female Willandra Lake femora have instances of transverse mid-shaft diameters and pilastric indices that fall above the range of the same-sexed recent Australian femora; the transverse condylar breadth of Lake Nitchie falls well beyond the recent Australian range; and Cossack has mid-shaft diameters that lie at the extreme of the recent Australian range (Table 12.26). Only the Kow Swamp femora cannot be distinguished from recent Australians in these regards. Therefore the male-like shape and size of the Lemdubu femora (Fig. 12.13) essentially reflects its ancient Sahulland status. In all these same respects, the gracile Leang Toge femur resembles recent Australian female femora, even if its shorter length $(43.6 \mathrm{~mm}$ shorter than the female Australian average) means that it is comparatively less slender.

In contrast to the large size of the femora, the Lemdubu patellae are patently small (measurement definitions taken from Martin and Saller 1957:570-1). The Lemdubu dimensions are consistently similar to those of the Leang Toge (right) patella (Table 12.27), and 6-10mm less than the Lake Nitchie patella on height, breadth and thickness (cf. Macintosh 1971:52). The Lemdubu patellae do not show a vastus notch, though their outline is concave here, nor a bipartite morphology or emarginate form (cf. Brothwell 1981:97, 99).

Maximum length of the right Lemdubu tibia can be estimated from its lengths of segments 3 and $4(\sim 173 \mathrm{~mm}$ and $\sim 111 \mathrm{~mm}$ respectively) as defined by Steele (1970; Steele and McKern 1969). Based on these estimates, tibia length would be $367.1 \pm 5.1 \mathrm{~mm}, 394.8 \pm 9.9 \mathrm{~mm}$ and $390.7 \pm 9.8 \mathrm{~mm}$, using the Mesoamerican, American white and Afro-American formulae respectively (Steele 1970; Steele and McKern 1969). The resulting range of 368-395mm closely matches the range measured by Rao (1966:269) for Australian female tibiae longer than the mean (364-402mm), so the Lemdubu tibia would be of above average length by recent female Australian standards. As the same would apply to Lemdubu Woman's femur, her relationship between femoral and tibia length would probably be similar to the usual situation among recent Australians. This point would certainly apply to both Lake Nitchie and Leang Toge, notwithstanding their great differences in body size. 
Table 12.26 Specimens and series arranged from most to least masculine in their femoral measurements (mm)

\begin{tabular}{|c|c|c|c|c|c|c|c|c|}
\hline \multirow{2}{*}{$\begin{array}{l}\text { SPECIMEN/ } \\
\text { SERIES }\end{array}$} & \multicolumn{5}{|c|}{$100 x$} & \multicolumn{3}{|c|}{ 100XM11/ } \\
\hline & M6 & M7 & M7/M6 & M8 & M11 & M12 & M12 & M21 \\
\hline Lake Nitchie $\bar{\sigma}$ & 32 & 28 & 114.3 & - & - & - & - & 89.5 \\
\hline Cossack $\bar{\sigma}$ & 35 & 28 & 125 & - & - & - & - & - \\
\hline Willandra Lake o & $\begin{array}{r}32.3 \\
(31-35)\end{array}$ & $\begin{array}{r}28.8 \\
(25-33)\end{array}$ & $\begin{array}{r}114.1 \\
(103-140)\end{array}$ & - & - & - & - & - \\
\hline Lemdubu $q$ & $\begin{array}{l}30.5 \\
(R, L)\end{array}$ & $\begin{array}{l}24 \\
(\mathrm{R})\end{array}$ & $\begin{array}{r}127.1 \\
(\mathrm{R})\end{array}$ & $\begin{array}{l}84 \\
(\mathrm{R})\end{array}$ & $\begin{array}{l}28 \\
(\mathrm{R})\end{array}$ & $\begin{array}{l}32 \\
(R)\end{array}$ & $\begin{array}{r}87.5 \\
(R)\end{array}$ & $\geq 71$ (R) \\
\hline Kow Swamp & - & - & $\sim 114$ & - & - & - & $\sim 72$ & - \\
\hline Willandra Lake 9 & $\begin{array}{r}29.6 \\
(28-31)\end{array}$ & $\begin{array}{r}27.5 \\
(26-31)\end{array}$ & $\begin{array}{r}108 \\
(94-119)\end{array}$ & - & - & - & - & - \\
\hline Australian $\bar{\sigma}$ & $\begin{array}{r}27.6 \\
(21-37)\end{array}$ & $\begin{array}{r}24.7 \\
(21-29)\end{array}$ & $\begin{array}{r}112.0 \\
(85-135)\end{array}$ & $\begin{array}{r}82.5 \\
(70-105)\end{array}$ & $\begin{array}{r}26.9 \\
(22-34)\end{array}$ & $\begin{array}{r}36.9 \\
(31-45)\end{array}$ & $\begin{array}{r}73.4 \\
(61-91)\end{array}$ & $\begin{array}{r}69.9 \\
(60-84)\end{array}$ \\
\hline Australian + & $\begin{array}{r}23.9 \\
(18-30)\end{array}$ & $\begin{array}{r}22.4 \\
(19-26)\end{array}$ & $\begin{array}{r}106.6 \\
(86-132)\end{array}$ & $\begin{array}{r}72.8 \\
(61-84)\end{array}$ & $\begin{array}{r}22.9 \\
(19-28)\end{array}$ & $\begin{array}{r}34.0 \\
(27-44)\end{array}$ & $\begin{array}{r}67.4 \\
(56-82)\end{array}$ & $\begin{array}{r}61.3 \\
(54-67)\end{array}$ \\
\hline Leang Toge $q$ & 22 & 23.5 & 93.6 & 71 & 24 & 36 & 66.7 & 59 \\
\hline
\end{tabular}

NB: M6 = sagittal mid-shaft diameter; M7 = transverse mid-shaft diameter; 100xM7/M6 = pilastric index; M8 = mid-shaft circumference; M11 = sagittal supracondylar diameter; M12 = transverse supracondylar diameter; 100xM11/M12 = popliteal index; M21 = transverse condylar breadth (Martin and Saller 1957:563-4). Cossack data from Freedman and Lofgren (1979:291). Willandra Lake data from Webb (1989:49), excluding estimated values. Kow Swamp values estimated from Kennedy (1984:Fig. 1), and include five males and one female. Recent Australian data from Davivongs (1963b:459). Leang Toge data from Jacob (1967:90)

Table 12.27 Liang Lemdubu: patella measurements $(\mathrm{mm})$ compared to those of Leang Toge

\begin{tabular}{lrrrlrrr}
\hline MEASUREMENT & \multicolumn{4}{c}{ LEANG } & & & LEANG \\
Greatest height (M1) & RIGHT & LEFT & TOGE & MEASUREMENT & 38 & 38.5 & 36 \\
Greatest thickness (M3) & 35 & 36 & 35 & Greatest breadth (M2) & 7 & 9 & 7.5 \\
Medial articular surface height (M5) & 17 & 17 & 18 & Articular surface height (M4) & 24 & 25 & 20 \\
\hline
\end{tabular}

Their tibio-femoral indices of 80.5 (Macintosh 1971:52) and 80.3 (Jacob 1967:91), respectively, closely match the averages of 80.5 and 80.6 recorded on Australian males and females (Rao 1966:270). It may also be noted that the Lemdubu tibia would have been longer than the single Willandra Lakes, female tibia which is complete enough for Webb (1989:51) to venture an estimate of its maximum length $(360 \mathrm{~mm})$.

The remaining Lemdubu tibia measurements are similar to the average values for female Australians (Table 12.28), apart from the flatter shape of the Lemdubu tibia at the nutrient foramen, and the low retroversion and inclination angles which reflect a straightish tibia shape, similar to the typical European condition (cf. Rao 1966:62). Lemdubu's platycnemia departs from the generally rounder tibiae at Willandra Lakes (average 66.1; Webb 1989:51) and Lake Nitchie (65.5; Macintosh 1971:52), so this is one feature where Lemdubu resembles Leang Toge (Jacob 1967:91) more so than Australian skeletons. However, the Leang Toge tibia is dissimilar from

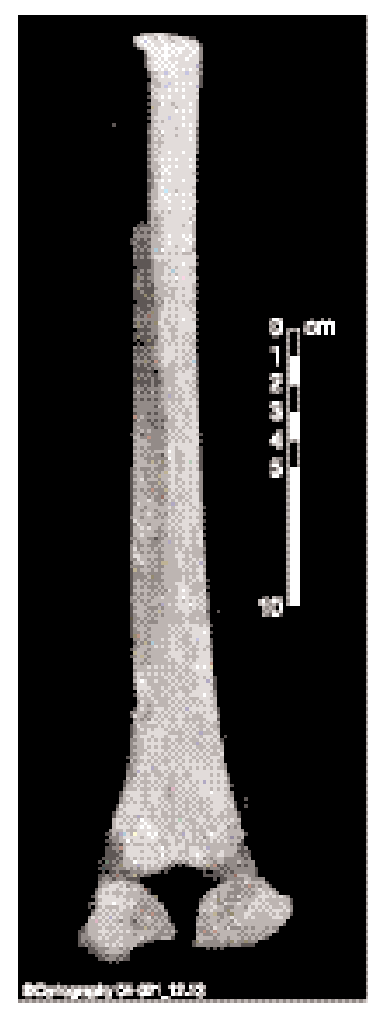

Figure 12.13 Liang Lemdubu: posterior view of the right femur (note the portion cut from the shaft for AMS dating and attempted stable isotope ratio analysis) 
Australian tibiae on other criteria too, such as its higher calibre index, and remarkably large retroversion and inclination angles as reported (Table 12.28).

The Lemdubu tibiae have a long shape at their mid-shaft and a hollowed lateral surface i.e. Hrdlička's Type 3 - while Leang Toge has a long oval shape - Hrdlička's Type 6 (Jacob 1967:91). The Type 3 form would be quite common among Australian Aborigines, especially the males, whereas the Type 6 morphology is rare among Australian males and even rarer among Australian females (cf. Rao 1966:61). The right Lemdubu tibia displays an ilio-tibial or lateral squatting facet, as found on Leang Toge (Jacob 1967:91) and around 80\% of Australians (Rao 1966:67); preservation is inadequate to tell whether a medial squatting facet is also expressed. As noted previously, the distal shaft of the right tibia bears a hole attributable to metastatic carcinoma (the corresponding area of the left tibia is not extant).

The left fibula of Lemdubu Woman is rugged, with marked furrows for the attachment of the soleus and peroneus longus muscles, and for the origins of the flexor hallucis longus and tibialis posterior muscles. It is also remarkably slender, with a minimum circumference recorded as $21 \mathrm{~mm}$, compared to a corresponding value of $28 \mathrm{~mm}$ on the extant right fibula fragments. The left-side value falls slightly below the recorded Australian range, while the right-side estimate equals the female Australian average (Rao 1966:272) and falls just beneath Leang Toge's value of $29 \mathrm{~mm}$ (Jacob 1967:92). The right-side maximum and minimum fibula diameters are respectively $10.5 \mathrm{~mm}$ and $8.5 \mathrm{~mm}$ on the extant fragments, slightly less than Leang Toge's values of $14.5 \mathrm{~mm}$ and nine millimetres as recorded at the mid-shaft (Jacob 1967:92). A slender fibula shape, noted to be a feature of Leang Toge (Jacob 1967:92) and Australian Aborigines (Rao 1966:75), would seem to be particularly a feature of Lemdubu Woman.

Table 12.28 Liang Lemdubu: tibia measurements ( $\mathrm{mm}$ ) compared to Leang Toge and Australian females

\begin{tabular}{|c|c|c|c|}
\hline MEASUREMENT & LEMDUBU & L. TOGE & AUSTRALIANS \\
\hline Sagittal diameter at nutrient foramen level (M8a) & $32(R)$ & - & $29.4 \pm 2.8$ \\
\hline Transverse diameter at nutrient foramen level (M9a) & $19(\mathrm{R})$ & - & $19.8 \pm 1.9$ \\
\hline Circumference at nutrient foramen level (M10a) & $82(\mathrm{R})$ & - & - \\
\hline Maximum diameter at mid-shaft (M8) & $27(\mathrm{R}), 28(\mathrm{~L})$ & $24.5(\mathrm{R}), 24(\mathrm{~L})$ & $25.6 \pm 2.5$ \\
\hline Transverse diameter at mid-shaft (M9) & $17(\mathrm{R}), 18(\mathrm{~L})$ & $16.5(\mathrm{R}), 18(\mathrm{~L})$ & $18.6 \pm 1.8$ \\
\hline Circumference at mid-shaft (M10) & $76(\mathrm{R}), 78(\mathrm{~L})$ & $66(\mathrm{R}), 65(\mathrm{~L})$ & $72.0 \pm 5.9$ \\
\hline Platycnemic index of Rao (M9ax100/M8a) & $59.4(\mathrm{R})$ & $<63.0$ & $67.6 \pm 5.5$ \\
\hline Platycnemic index of Jacob (M9x100/M8) & $63.0(\mathrm{R}), 64.3(\mathrm{~L})$ & $67.4(\mathrm{R}), 75.0(\mathrm{~L})$ & - \\
\hline Calibre index & $\sim 19$ & $20.3(\mathrm{R})$ & $17.6 \pm 1.1$ \\
\hline Sagittal diameter of distal epiphysis (M7) & $\sim 33(\mathrm{R})$ & - & $32.4 \pm 1.7$ \\
\hline Retroversion angle & $\sim 11^{\circ}(\mathrm{R})$ & $30^{\circ}(\mathrm{R})$ & $18.0^{\circ} \pm 4.1$ \\
\hline Inclination angle & $\sim 9^{\circ}(\mathrm{R})$ & $21^{\circ}(\mathrm{R})$ & $14.1^{\circ} \pm 3.8$ \\
\hline
\end{tabular}

NB: Leang Toge from Jacob (1967:91) and Australian Aborigines from Rao (1966:269-71). Calibre index is minimum circumference x 100 divided by physiological length; the estimate for the Lembubu skeleton is indicative only. M: Martin and Saller (1957:573-4)

\section{The extremities}

As noted in in the discussion above on the disposition of the bones, the majority of the extremity bones excavated at Lemdubu would not appear to relate to Lemdubu Woman. The distal pedal phalanx from Spit 1 is adult, as indicated by its fused epiphyses, and short at $14.5 \mathrm{~mm}$ in length, which might point to a female status. It is burnt, as is the right fifth proximal manual phalanx from Spit 10, which also has fused epiphyses. Its phalanx length of $29 \mathrm{~mm}$ falls at the bottom of the male Australian range recorded by Rao (1966:43). The distal pedal phalanx (second digit) from Spit 11 measures 12mm in length, which falls within the range of 8-21mm recorded by Rao (1966:108) on recent male Australians. It is adult and could conceivably have derived from Lemdubu Woman, as 
could the small calcaneus fragment from Spit 12. A proximal fragment from a left fourth metacarpal, recovered from Spit 20, is of a size that would be consistent with a tallish individual like Lemdubu Woman. The talus fragments from the base of the excavation are too incomplete to allow any anatomically useful observations. Finally, two right lunate bones are present, a small burnt specimen from Spit 7 (which could relate to the other extremity bones from Spits 1 and 10) and a larger, unburnt specimen from Spit 19. Their measurements are given in Table 12.29.

Table 12.29 Liang Lemdubu: measurements $(\mathrm{mm})$ of the two right lunate bones

\begin{tabular}{lrrrrrrrrrrrr}
\hline SPECIMEN & M1 & M2 & M3 & M4 & M5 & M6 & M7 & M8 & M9 & M10 & M11 & M12 \\
\hline Spit 7 & 21 & 17 & 13 & 13 & 10 & 13 & 10 & 10.5 & 10 & 8 & 7 & 1.5 \\
Spit 19 & 21.5 & 21 & 15.5 & 15 & 18 & 16.5 & 11 & 12 & 5 & 14 & 7.5 & 3 \\
\hline
\end{tabular}

NB: M: Martin and Saller (1957:544-5)

\section{Stature and postcranial robustness}

The two maximum limb bone lengths of Lemdubu Woman that allow a useful estimate of her stature during life are the left humerus length of around $313 \mathrm{~mm}$, and right tibia length of 365$400 \mathrm{~mm}$. The most suitable regression formulae to estimate stature would be those which both use maximum limb bone lengths for the humerus and tibia, and are derived from female skeletons of a population in the same region. Only the study by Bergman and The (1955) on Javanese corpses fits the bill. However, because they estimated corpse length rather than stature, two centimetres should be subtracted from the resulting estimate (Snell 1949:358). The humerus would therefore lead to an estimated stature of $165.9 \pm 4.5 \mathrm{~cm}$, likewise the tibia an estimate of $162-173 \pm 3.9 \mathrm{~cm}$ (Bergman and The 1955:200) or $167.5 \mathrm{~cm}$ as a middling estimate. The relatively short vertebral discs and, therefore, short vertebral column of Lemdubu Woman (given her long limbs by female standards) might suggest an accommodatory reduction of her estimated stature. However, the appropriate degree of reduction would be difficult to stipulate, especially as her tall cranium (taller even than the recent male Australian average) would suggest the contrary accommodation, and, as noted above, least-squares regression estimates of a tall individual's stature from that individual's limb-bone lengths would tend to produce conservative results. Hence, the humerus-based estimate of $166 \mathrm{~cm}$ for Lemdubu Woman's stature is probably the best available.

In contrast, Leang Toge's stature estimates would be $143.0 \mathrm{~cm}$ (left femur), $143.9 \mathrm{~cm}$ (right tibia), $149.3 \mathrm{~cm}$ (right humerus), $151.5 \mathrm{~cm}$ (left radius), and $152.5-155.2 \mathrm{~cm}$ (ulnae) with reference to female Javanese regression formulae, employing Jacob's measurements of the particular limb bone length definitions given by Bergman and The (1955:198). These stature estimates compare well with Jacob's (1967:94) own estimate of $148.4 \mathrm{~cm}$. The stature of Leang Toge would therefore have been $11-23 \mathrm{~cm}$ less than that of Lemdubu Woman, or $17 \mathrm{~cm}$ as a middling estimate.

Lemdubu Woman's stature of around $166 \mathrm{~cm}$ would be very similar to the average male stature found among recent Australian Aborigines and, accordingly, around $10 \mathrm{~cm}$ taller than the recent female Australian average (cf. Kirk 1981:91-4). This tall stature is in accord with the large size of other documented Sahulland skeletons of Pleistocene age, as reflected by the ulna length of Lake Mungo 3, which lies at the top of the recent Australian male range, and the large stature of the Coobool Creek and Nacurrie males as estimated from their cranial dimensions (Brown 2000:747). It is also in accord with the stature estimates of the ancient Willandra Lake skeletal collections studied by Webb (1989:92-142), whether we use Webb's estimates using Afro-American regression formulae (Webb 1989:20), or estimates based on Javanese formulae regressed against maximum limb-bone lengths (Table 12.30). Estimates for males range from the recent Australian average to a value around $15 \mathrm{~cm}$ higher, while estimates for females fall within a tighter range between the recent Australian average and the estimated stature of Lemdubu Woman. The huge stature of the virtually complete Lake Nitchie male, placed reliably at $187.7 \mathrm{~cm}$ (Macintosh 1971:51), has already been alluded to. 
As discussed above, when considered in terms of muscular markings, the postcranial robustness of Lemdubu Woman is not particularly marked, lying more or less between the average conditions that would pertain to recent male and female Australians. Pronounced postcranial robustness is evident, however, when considered in terms of the thickness of the shaft bone. At the cross-sections exposed by breakages in the bones near the mid-shaft of the femur and humerus, the combined thicknesses of the cortical bone always exceeded the thickness of the medullary cavity along the same axis, and was sometimes thicker on just one of the sides. In the case of the humerus, the relative thickness of Lemdubu Woman's cortical bone is very similar to that of a Willandra Lake humerus that Webb (1989:48) singled out as having the thickest cortical bone in the series (Table 12.31). With regard to the femur, the percentage of Lemdubu Woman's medio-lateral axis that is cortical bone is very similar to the average values recorded for other specimens of Homo sapiens, including those in Australia, but in the antero-posterior axis, Lemdubu Woman approximates the average recorded for $H$. erectus. Even here, however, the variation among $H$. sapiens (including recent Australians) is so wide that the Lemdubu value would comfortably fall within the sapient range (Table 12.31).

At Lemdubu Woman's femoral mid-section, the medullary area is circa $85 \mathrm{~mm}^{2}$, cortical area $366 \mathrm{~mm}^{2}$, and total cross-sectional area $451 \mathrm{~mm}^{2}$. A breakage approximately $35 \%$ along the femoral shaft from its distal epiphysis naturally displayed thinner cortical bone, but even here the cortex is thick, with an estimated area of $338 \mathrm{~mm}^{2}$, compared to total cross-sectional area of $546 \mathrm{~mm}^{2}$, and medullary area of $208 \mathrm{~mm}^{2}$. The estimated values at the humerus mid-section are $23 \mathrm{~mm}^{2}$ for the medullary area, $145 \mathrm{~mm}^{2}$ for cortical area, and $168 \mathrm{~mm}^{2}$ for total cross-sectional area. When the estimated cortical area is expressed as a percentage of the total cross-sectional area, thickness of the bone approximates the condition observed among Neandertals, and lies well above the recent Homo sapiens average (Table 12.32). This does not however reflect a Neandertal-like shape of the femoral and humerus cross-sections; in particular, Lemdubu Woman has the strongly developed pilaster of early, anatomically modern $H$. sapiens rather than the round femora of the Neandertals (Pearson 1999:241; cf. Ruff et al. 1993:Fig. 1) or, for that matter, H. erectus (Kennedy 1984:166). Rather, it emphasises the relatively great thickness of the cortical bone of Lemdubu Woman.

\section{Discussion and Conclusion}

As well as discussing the terminal Pleistocene age of the fragments assignable to Lemdubu Woman, this paper shows that the biological affinities confirm the burial's Late Pleistocene Sahulland status. It is only in the comparison with ancient Australians that Lemdubu Woman registers a higher frequency of matches (11) compared to mismatches (6). This strong agreement specifically reflects the common features of large size (tall stature, long limb bones, large cranium) and robust cranial anatomy (Table 12.33). At the detailed level, some differences do emerge between Lemdubu Woman and penecontemporary fossils to the south, as in mandibular anatomy (Table 12.14), and various divergences from the Kow Swamp and Coobool Creek morphological pattern summarized by Brown (1989:169-74). For example, the Lemdubu mandible does not have the particularly tall corpus noted for the ancient Murray Valley mandibles, the lateral maxillary incisors are not particularly robust, and the cranium is not markedly (not at all) dolichocranic or characterized by thick vault bone. Further Late Pleistocene burials from northern Sahulland would be required to assess whether these differences reflect individual, geographic or chronological variation.

Even in those cases where a distinction may be noted between the anatomy of Lemdubu Woman and ancient Australian fossils to the south, a similarity with the osteology of recent Australians usually emerges (Table 12.33), reinforcing the burial's affinity with southwest Pacific populations. Thickness of the limbs' cortical bone is the sole aspect where Lemdubu Woman's 
Table 12.30 Ancient Willandra Lake burials estimated statures (cm) (from Webb 1989:92-142)

\begin{tabular}{|c|c|c|c|c|c|}
\hline $\begin{array}{l}\text { Males } \\
\text { Specimen }\end{array}$ & Stature & $\begin{array}{l}\text { Indeterminate } \\
\text { Specimen }\end{array}$ & Stature & $\begin{array}{l}\text { Females } \\
\text { Specimen }\end{array}$ & Stature \\
\hline WL67 & $177-180$ [171-177] & WL117 (if $\bar{\sigma}$ ) & 169 & WL25 & $161-165$ [162] \\
\hline WL107 & 170 & WL117 (if 9 ) & 166 & WL72 & $159-162$ [160] \\
\hline WL106 & $164-173$ [162-171] & WL6 (if $\bar{\sigma}$ ) & 158 [156] & WL45 & $159-160$ [162.5] \\
\hline WL110 & 164 [162] & WL6 (if 9 ) & $153[152]$ & & \\
\hline
\end{tabular}

NB: ancient status determined either by advanced mineralization (WL6, WL25, WL110), or carbonate encrustation (WL45, WL67, WL106, WL107, WL117), or both (WL72). Webb offers both male and female stature estimates for several of these burials; both estimates are shown here when he considered the burial's sex to be indeterminate. Estimates in square brackets are derived from Javanese regression formulae (Bergman and The 1955:200); these however cannot be used when the femur is the limb bone allowing a stature estimate, as Bergman and The measured femoral length in natural position, while Webb's estimates are maximum lengths of the limb bone

Table 12.31 Liang Lemdubu: compared on percentage of mid-shaft diameter made up of cortical bone

\begin{tabular}{lrrrr}
\hline SPECIMEN/SERIES & $\begin{array}{r}\text { FEMUR } \\
\text { MEDIO-LATERAL }\end{array}$ & $\begin{array}{r}\text { FEMUR } \\
\text { ANTERO-POSTERIOR }\end{array}$ & $\begin{array}{r}\text { HUMERUS } \\
\text { MEDI0-LATERAL }\end{array}$ & $\begin{array}{r}\text { HUMERUS } \\
\text { ANTER0-POSTERIOR }\end{array}$ \\
\hline Lemdubu Woman & $\sim 57.6$ & $\sim 61.5$ & $\sim 68.3$ & $\sim 53.6$ \\
Willandra Lakes & $\sim 37.8$ & $\sim 51.5$ & $\sim 55.1, \sim 63.2$ & $\sim 61.0, \sim 60.4$ \\
Kow Swamp & $41.7-68.2$ & $37.5-50.9$ & - & - \\
Murray Valley males & $58.3 \pm 6.3$ & $54.6 \pm 5.7$ & - & - \\
Murray Valley females & $54.2 \pm 7.2$ & $50.5 \pm 8.9$ & - & - \\
Tasmanian males & $53.3 \pm 9.9$ & $51.8 \pm 13.8$ & - & - \\
Tasmanian females & $59.2 \pm 19.5$ & $57.5 \pm 11.2$ & - & - \\
Romano-British males & $57.6 \pm 7.8$ & $58.1 \pm 7.6$ & - & - \\
Romano-British females & $55.3 \pm 11.1$ & $55.2 \pm 7.5$ & - & - \\
Homo erectus & $62.3 \pm 5.0$ & $62.8 \pm 7.3$ & - & - \\
\hline
\end{tabular}

NB: Willandra Lake values estimated from photographs of the femur of WL107 (Webb 1989:Plate 1) and the the humeri of WL110 (Webb 1989:Plate 16). 0ther comparative data from Kennedy (1984)

Table 12.32 Liang Lemdubu: compared cortical area as a percentage of total cross-sectional area on the femur and humerus

\begin{tabular}{|c|c|c|c|c|}
\hline & LEMDUBU WOMAN & NEANDERTALS & $\begin{array}{r}\text { EARLY MODERN } \\
\text { H. SAPIENS }\end{array}$ & $\begin{array}{r}\text { RECENT } \\
H . \text { SAPIENS }\end{array}$ \\
\hline Distal femur ( 35\% along shaft length) & $\sim 61.9 \%$ & $\sim 66 \%$ & $\sim 55 \%$ & $\sim 55 \%$ \\
\hline Medial femur ( 50\% along shaft length) & $\sim 81.2 \%$ & $\sim 78 \%$ & $\sim 79 \%$ & $\sim 70 \%$ \\
\hline Medial humerus ( 50\% along shaft length) & $\sim 86.3 \%$ & $78.6 \%$ & - & $67.6 \%$ \\
\hline
\end{tabular}

NB: averages for Neandertals, early modern Homo sapiens, and recent Homo sapiens estimated from Ruff et al. (1993:Figure 2) or taken from Ruff et al. (1993:37)

skeletal morphology clearly departs from both ancient and recent Australians' usual condition (as currently documented). And in at least some cases where Lemdubu Woman could not be claimed to be similar to either ancient or recent Australians (+/- in Table 12.33), this reflects the skeleton's 'hyper-Australian' attributes. For instance, her body build was more linear than is the case with the ancient Australian from Lake Nitchie, or with most recent Australians, but as detailed in the post cranial description above, linearity of body build - elongated distal limbs compared to proximal limb-bone lengths, long limb bones compared to the length of the vertebral column, and gracile epiphyses compared to limb-bone lengths - is a distinguishing trait of Australian Aborigines compared to most other recent populations. Where Lemdubu Woman differs most clearly from recent Australians is in her larger body size and greater cranial robustness, two general attributes that also distinguish ancient southeast Australian fossils from recent Australians (Brown 1987; 1989:172).

Lemdubu Woman rarely agrees with the morphological attributes of the middle Holocene Flores' specimens (Table 12.33), as best represented by the Leang Toge skeleton. Size and robustness distinctions dominate the differences, along with the far more linear build of the Aru 
12.33 Liang Lemdubu: summary of Lemdubu Woman and Leang Toge skeletal comparisons

\begin{tabular}{|c|c|c|c|c|c|c|}
\hline \multirow[b]{2}{*}{ SKELETAL ASPECT } & \multicolumn{3}{|c|}{ LEMDUBU WOMAN } & \multicolumn{3}{|c|}{ LEANG TOGE } \\
\hline & $A A$ & RA & $\mathrm{FL}$ & $A A$ & RA & $L M$ \\
\hline Tooth size & + & + & - & - & - & - \\
\hline Cranial size & ++ & - & - & - & + & - \\
\hline Craniometrics & + & - & - & - & + & - \\
\hline Cranial anatomy & ++ & - & - & - & + & - \\
\hline Mandibular anatomy & $+/-$ & + & - & $+/-$ & + & - \\
\hline Mandibular size & $+/-$ & - & + & + & - & + \\
\hline Mandibular shape & - & + & + & $+/-$ & $+/-$ & + \\
\hline Vertebral disc dimensions & $?$ & $+/-$ & - & $?$ & - & - \\
\hline Clavicle & - & + & $?$ & $?$ & $?$ & $?$ \\
\hline Scapula size & + & - & - & - & + & - \\
\hline Scapula anatomy & $?$ & - & + & $?$ & - & + \\
\hline Humerus length & + & - & - & - & - & - \\
\hline Humerus shape & - & + & + & - & + & + \\
\hline Radius length & + & - & - & - & $+/-$ & - \\
\hline Radius shape & $?$ & $+/-$ & $+/-$ & $?$ & $+/-$ & $+/-$ \\
\hline Ulna & $?$ & + & - & $?$ & - & - \\
\hline Innominates & + & $+/-$ & - & - & + & - \\
\hline Femur size & + & - & - & - & - & - \\
\hline Femur robustness & + & - & - & - & + & - \\
\hline Small patella & - & $?$ & + & - & $?$ & + \\
\hline Tibia shape & - & + & $+/-$ & - & - & $+/-$ \\
\hline Slender fibula & $?$ & + & + & $?$ & + & + \\
\hline Proximal/distal limb bone relationship & $+/-$ & $+/-$ & $+/-$ & + & + & $+/-$ \\
\hline Linearity of build & $+/-$ & $+/-$ & - & + & + & - \\
\hline Stature & + & - & - & - & - & - \\
\hline Thick cortex (limb bones) & - & - & $?$ & $?$ & $?$ & $?$ \\
\hline Total matches/mismatches & $\begin{array}{l}11+/++ \\
4+/-, 6-\end{array}$ & $\begin{array}{c}8+/++ \\
5+/-, 12-\end{array}$ & $\begin{array}{c}6+, 3+/- \\
15-\end{array}$ & $\begin{array}{c}3+, 2+/- \\
14-\end{array}$ & $\begin{array}{c}11+, 3+/- \\
9-\end{array}$ & $\begin{array}{c}6+, 3+/- \\
15-\end{array}$ \\
\hline
\end{tabular}

NB: $\mathrm{AA}=$ ancient Australians, $\mathrm{RA}=$ recent Australians, $\mathrm{FL}=$ Flores, $\mathrm{LM}=$ Lemdubu Woman $;++=$ strong agreement, $+=$ agreement, $+/-=$ ambiguous, $-=$ disagreement, ? = comparison unavailable

skeleton, but there are also other divergences as in the detail of the mandibular morphology (Table 12.14). However, while the Leang Toge and Lemdubu skeletons clearly represent different populations, it is far less apparent that Leang Toge could be osteologically distinguished from recent Australian Aborigines. Storm (1995:98) noted that 'Liang Toge shows a combination of some characters resembling the morphology often found in recent female Australian skulls'. This conclusion is reinforced here in cranial size (Fig. 12.7), craniometrics (Table 12.12), overall cranial anatomy (Figs 12.8 and 12.9), and, notwithstanding Leang Toge's small stature, proximal-distal limb bone proportions and many shape details of the limb bones (Table 12.33). To think of Lemdubu Woman as ancient Australian (Sahulland), and Leang Toge as similar to recent Australians, would certainly allow us to propose deriving, at least in part, the ancestry of the middle Holocene inhabitants of Flores from the Pleistocene inhabitants of northern Sahulland.

Accepting the Pleistocene Sahulland status of Lemdubu Woman, we should consider how this new find reflects on the much-vaunted (and debated) distinction between 'robust' and 'gracile', ancient Australians (Brown 1987; Bulbeck 2001; Thorne 1977; Webb 1989:73-6). Thick bone on the cranial vault is one debated component of the so-called robust morphology (Brown 1987:48-50, 61; Thorne 1977:191), and in this respect Lemdubu Woman would be decidedly 'gracile'. The flat, receding frontal bone of certain Murray Valley specimens has also been invoked 
as a component of the robust morphology, although this feature is now convincingly related to cranial deformation (Antón and Weinsten 1999; Brown 1981). The naturally receding frontal of the very robust WL50 specimen (Hawks et al. 2000) may help to rehabilitate the claimed assocation, but in that case, Lemdubu's rounded frontal would make it truly gracile. A third component is the distinction between huge (robust) and relatively small (gracile) crania at Willandra Lakes, which can be attributed to the enormous elapse of time represented by those specimens, even if the chronological details are not as yet entirely clear (Bulbeck 2001:98; see Fig. 12.7, this paper). Lemdubu would fit into neither of these categories as its cranial size fits centrally in the terminal Pleistocene Sahulland range. Fourth is the greater size and robustness (but also variations in angularity in the parietal region unrelated to cranial deformation). Lemdubu Woman would be considered robust on this criterion but, as emphasised by Brown (1987:61), so would the Keilor specimen from terminal Pleistocene Victoria, a specimen frequently held up as gracile. Once differences that could be attributed to sex are removed, the main difference between Lemdubu and Keilor may lie in the greater angulation of the Lemdubu cranium's parietal contour (cf. Weidenreich 1945), and so Lemdubu could be considered more robust on those terms.

From the above, it would seem that the 'robust' and 'gracile' categories, despite their continued retention as objective classifications in some recent studies (e.g. Adcock et al. 2000), are poorly defined in the terminal Pleistocene Sahulland context. These morphological categories are based on components which often appear contradictory rather than correlated, and so attempting to classify a specimen as either robust or gracile may hinder our appreciation of that specimen's overall morphology. The Lemdubu skeleton does not fit with the view of these two 'morphologies' as espoused, for instance, by Thorne (e.g. Adcock et al. 2000; Sim and Thorne 1990; Thorne 1977, 1980; Thorne and Wilson 1977). It may be more productive, instead, to try and understand spatial and chronological variation among Sahulland's occupants in terms of modern evolutionary theory. For instance, while this paper is not the place for an extended discussion, it may be suggested that Lemdubu Woman's combination of thick cortical limb bone, robust femora compared to gracile arm bones, and markedly linear build reflects in part retention of early modern Homo sapiens' features and, in part, adaptation to a tropical environment during a period when temperatures generally were dropping (Pearson 1999; cf. Ruff et al. 1993).

In summary, this article certifies the terminal Pleistocene status of the human burial excavated at the Lemdubu site in the Aru Islands, and concurrently, shows its two unique credentials. It is the only terminal Pleistocene Sahulland specimen whose postcranial skeleton has been published in any detail, and it is the only described, terminal Pleistocene representative of the tropical belt of Sahulland.

\section{Acknowledgments}

I would like to thank Matthew Spriggs and Sue O'Connor for giving me the opportunity to work on the Lemdubu human remains and for their discussions and advice on issues of stratigraphic association, chronology and likely burial practices. Thanks are also due to Frédérique Valentin who provided many useful comments as peer reviewer for the article. 


\section{References}

Adcock, G.J., E.S. Dennis, S. Easteal, G.A. Huttley, L.S. Jermlin, W.J. Peacock, and A. Thorne. 2001. Mitochondrial DNA sequences in ancient Australians: implications for modern human origins. Proceedings of the National Academy of Sciences 98(2):537-42.

Antón, S.C. and K.J. Weinstein. 1999. Artificial cranial deformation and fossil Australians revisited. Journal of Human Evolution 36:195-209.

Arsuaga, J.L. and J.M. Carretero. 1994. Multivariate analysis of the sexual dimorphism of the hip bone in a modern human population and in early hominids. American Journal of Physical Anthropology 93:241-57.

Aufderheide, A.C. and C. Rodríguez-Martín. 1998. The Cambridge Encyclopedia of Human Paleopathology. Cambridge: Cambridge University Press.

Bergman, R.A.M. and T.H. The. 1955. The length of the body and long bones of the Javanese. Documenta de Medecina Geographica et Tropica 7:197-214.

Berry, A.C. 1974. The use of non-metrical variations of the cranium in the study of Scandinavian population movements. American Journal of Physical Anthropology 40:345-58.

von Bonin, G. 1963. The Evolution of the Human Brain. Chicago: University of Chicago Press.

Brace, C.L. and R.J. Hinton. 1981. Oceanic tooth-size variations as a reflection of biological and cultural mixing. Current Anthropology 22:549-69.

Brooks, S. and J.M. Suchey. 1990. Skeletal age determination based on the os pubis: a comparison of the AcsádiNemeskéri and Suchey-Brooks methods. Journal of Human Evolution 5:227-38.

Brothwell, D.R. 1981. Digging up Bones. Third edition. Oxford: British Museum (Natural History)/Oxford University Press.

Brown, P. 1981. Artificial cranial deformation: a component in the variation in Pleistocene Australian Aboriginal crania. Archaeology in Oceania 16:156-67.

Brown, P.J. 1982. Coobool Creek: A Prehistoric Australian Hominid Population. Unpublished PhD thesis, The Australian National University, Canberra.

Brown, P. 1987. Pleistocene homogeneity and Holocene size reduction: the Australian human skeletal evidence. Archaeology in Oceania 22:41-67.

Brown, P. 1989. Coobool Creek. Canberra: The Australian National University, Terra Australis 13.

Brown, P. 1992. Pleistocene change in Australian Aboriginal tooth size: dental reduction or relative expansion? In T. Brown and S. Molnar (eds), Craniofacial Variation in Pacific Populations: Papers Presented at a Symposium Honolulu, Hawaii, May 30, 1991, pp. 33-51. Adelaide: The University of Adelaide.

Brown, P. 1994. A flawed vision: sex and robusticity on King Island. Australian Archaeology 38:1-7.

Brown, P. 1995. Still flawed: a reply to Pardoe (1994) and Sim and Thorne [sic!] (1994). Australian Archaeology 41:26-9.

Brown, P. 2000. Australian Pleistocene variation and the sex of Lake Mungo 3. Journal of Human Evolution 38:743-9.

Brown, P. 2001. Peter Brown's Australian Palaeoanthropology. URL: http://metz.une.edu.au/ pbrown3/ausindex.html.

Brown, T., S.K. Pinkerton, and W. Lambert. 1979. Thickness of the cranial vault in Australian Aboriginals. Archaeology and Physical Anthropology in Oceania 14:54-71.

Bulbeck, F.D. 1981. Continuities in Southeast Asian Evolution Since the Late Pleistocene. Unpublished M.A. thesis, The Australian National University, Canberra.

Bulbeck, F.D. 1992. A Tale of Two Kingdoms: The Historical Archaeology of Gowa and Tallok, South Sulawesi, Indonesia. Unpublished PhD thesis, The Australian National University, Canberra.

Bulbeck, F.D. 1993. Report on the human osteological remains from Tanjung Pinang, Morotai Island, Maluku Utara, Indonesia. In Archaeological Survey and Excavation in the Halmahera Island Group, Maluku Utara, Indonesia. Unpublished report for the Australasian Indonesian project.

Bulbeck, D. 1997. Seriated dendrograms (Appendix B). In A. Flavel, Sa-Huynh-Kalanay? Analysis of the Prehistoric Decorated Earthenware of South Sulawesi in an Island Southeast Asian Context, pp. 212-25. Unpublished B.Sc. Hons subthesis, University of Western Australia, Perth.

Bulbeck, D. 2000a. Dental morphology at Gua Cha, West Malaysia, and the implications for 'Sundadonty'. Indo-Pacific Prehistory Association Bulletin 19:17-41.

Bulbeck, D. 2000b. Multivariate statistical analysis of the Gua Peraling 4 cranium (Appendix 7). In Adi bin Haji Taha, Archaeological Investigations in Ulu Kelantan, Peninsular Malaysia, unpaginated. Unpublished PhD thesis, The Australian National University, Canberra.

Bulbeck, F.D. 2001. Robust and gracile Australian crania: the tale of the Willandra Lakes. In T. Simanjuntak, B. Prasetyo, and R. Handini (eds), Sangiran: Man, Culture and Environment in Pleistocene Times, pp. 60-106. Jakarta: Yayasan Obor Indonesia/The National Research Centre of Archaeology/École Française d'ExtrêmeOrient. 
Bulbeck, D. 2004. Appendix 1: Human remains from Kria Cava and Toé Cave, Papua, Indonesia. In J.M. Pasveer, The Djief Hunters: 26,000 Years of Rainforest Exploitation on the Bird's Head of Papua, Indonesia, pp. 379-98. Modern Quaternary Research in Southeast Asia 17. Leiden: A.A. Balkema.

Davivongs, V. 1963a. The pelvic girdle of the Australian Aborigine; sex differences and sex determination. American Journal of Physical Anthropology 21:443-55.

Davivongs, V. 1963b. The femur of the Australian Aborigine. American Journal of Physical Anthropology 21:457-67.

van Dongen, R. 1963. The shoulder girdle and humerus of the Australian Aborigine. American Journal of Physical Anthropology 29:469-88.

Formicola, V. 1993. Stature reconstruction from long bones in ancient population samples: an approach to the problem of its reliability. American Journal of Physical Anthropology 90:351-8.

Freedman, L. and M. Lofgren. 1979. Human skeletal remains from Cossack, Western Australia. Journal of Human Evolution 8:283-99.

Freedman, L. and M. Lofgren. 1983. Human skeletal remains from Lake Tandou, New South Wales. Archaeology in Oceania 18:98-105.

Gilbert, B.M. and T.W. McKern. 1973. A method for ageing the female os pubis. American Journal of Physical Anthropology 38:31-8.

Hawks, J., S. Oh, K. Hunley, S. Dobson, G. Cabana, P. Dayula, and M.H. Wolpoff. 2000. An Australasian test of the recent African origin theory using the WLH-50 calvarium. Journal of Human Evolution 39:1-22.

Hillson, S. 1996. Dental Anthropology. Cambridge: Cambridge University Press.

Howells, W.W. 1973. Cranial Variation in Man. Cambridge, Mass.: Harvard University Press.

Hrdlička, A. 1928. Catalogue of human crania in the United States National Museum collections. Proceedings of the U.S. National Museum 71:1-140.

Jacob, T. 1967. Some Problems Pertaining to the Racial History of the Indonesian Region. Utrecht: Netherlands Bureau for Technical Assistance.

Kellock, W.L. and P.A. Parsons. 1971. A comparison of the incidence of minor nonmetrical cranial variants in Australian Aborigines with those of Melanesia and Polynesia. American Journal of Physical Anthropology 33:235-40.

Kennedy, G.E. 1984. Are the Kow Swamp hominids 'archaic'? American Journal of Physical Anthropology 65:163-8.

Kirk, R.L. 1981. Aboriginal Man Adapting. Oxford: Clarendon Press.

Larnach, S.L. and L. Freedman. 1964. Sex determination of crania from coastal New South Wales. Records of the Australian Museum 26:295-308.

Larnach, S.L. and N.W.G. Macintosh. 1966. The Craniology of the Aborigines of Coastal New South Wales. Sydney: University of Sydney. Oceania Monographs 13.

Larnach, S.L. and N.W.G. Macintosh. 1970. The Craniology of the Aborigines of Queensland. Sydney: University of Sydney. Oceania Monographs 15.

Larnach, S.L. and N.W.G. Macintosh. 1971. The Mandible in Eastern Australian Aborigines. Sydney: University of Sydney. Oceania Monographs 17.

Lundy, J.K. 1980. The mylohyoid bridge in the Khoisan of southern Africa and its unsuitability as a Mongoloid genetic marker. American Journal of Physical Anthropology 53:43-8.

Macintosh, N.W.G. 1971. Analysis of an Aboriginal skeleton and a pierced tooth necklace from Lake Nitchie. Anthropologie 9(1):49-62.

Martin, R and K. Saller. 1957. Lehrbuch der Anthropologie. Band I. Fifth edition. Stuttgart: Gustav Fischer Verlag.

Miles, A.E.W. 1963. The dentition in the assessment of individual age in skeletal material. In D.R. Brothwell (ed.), Dental Anthropology, pp. 191-209. London: Pergamon Press.

Ousley, S.D. and R.L. Jantz. 1996. Fordisc 2.0: Personal Computer Forensic Discriminant Functions. Knoxville: University of Tennessee.

Pearson, O.M. 1999. Postcranial remains and the origin of modern humans. Evolutionary Anthropology 9:229-47.

Penrose, L.S. 1954. Distance, size and shape. Annals of Eugenics 18:337-43.

Pietrusewsky, M. 1984. Metric and Non-metric Cranial Variation in Australian Aboriginal Populations Compared with Populations from the Pacific and Asia. Canberra: Australian Institute of Aboriginal Studies. Occasional Papers in Human Biology 3.

Raath, P. 1996. A Grave Look at Western Australian Prehistory. Unpublished B.Sc. Hons subthesis, University of Western Australia, Perth.

Rao, P.D.P. 1966. The Anatomy of the Distal Limb Segments of the Aboriginal Skeleton. Unpublished PhD thesis, University of Adelaide, Adelaide.

Ray, L.J. 1959. Metrical and non-metrical features of the clavicle of the Australian Aboriginal. American Journal of Physical Anthropology 17:217-26. 
Richards, L.C. and T. Brown. 1981. Dental attrition and degenerative arthritis of the temporomandibular joint. Journal of Oral Rehabilitation 8:293-307.

Rothschild, B.M., I. Hershkovitz, and O. Dutour. 1998. Clues potentially distinguishing lytic lesions of multiple myeloma from those of metastatic carcinoma. American Journal of Physical Anthropology 105:241-50.

Ruff, C.B., E. Trinkaus, A. Walker, and C.S. Larsen. 1993. Postcranial robusticity in Homo. I: temporal trends and mechanical interpretation. Journal of Physical Anthropology 91:21-53.

Scott, G.R. and C.G. Turner II. 1997. The Anthropology of Modern Human Teeth. Cambridge: Cambridge University Press.

Sim, R. and A. Thorne. 1990. Pleistocene human remains from King Island, southeastern Australia. Australian Archaeology 31:44-51.

Snell, C.A.R.D. 1938. Menschelijke Skeletresten uit de Duinfromatie van Java's Zuidkust nabij Poeger (z-Banjoewangi). Surabaya: G. Kolff.

Snell, C.A.R.D. 1949. Human skeletal remains from Gol Ba'it, Sungai Siput, Perak, Malay Peninsula. Acta Neerlandica Morphologicae et Pathologicae 6:353-77.

Steele, D.G. 1970. Estimation of stature from fragments of limb bones. In T.D. Stewart (ed.), Personal Identification in Mass Disasters, pp. 85-97. Washington: National Museum of Natural History, Smithsonian Institute.

Steele, D.G. and T.W. McKern. 1969. A method for assessment of maximum long bone length and living stature from fragmentary long bones. American Journal of Physical Anthropology 31:215-28.

Storm, P. 1995. The Evolutionary Significance of the Wajak Skulls. Leiden: National Natuurhistorisch Museum. Scripta Geologica 110.

Szilvássy, J. 1988. Altersdiagnose am Skelett. In R. Knußman (ed.), Wesen und Methoden der Anthropologie, 1. Teil, Wissenschaftheorie, Geschichte, morphologischen Methoden, pp. 421-42. Stuttgart: Gustav Fischer Verlag.

Thorne, A.G. 1975. Kow Swamp and Lake Mungo: Toward a Craniology of Early Man in Australia. Unpublished $\mathrm{PhD}$ thesis, University of Sydney, Sydney.

Thorne, A.G. 1977. Morphological contrasts in Pleistocene Australians. In J. Allen, J. Golson, and R. Jones (eds), Sunda and Sahul, pp. 187-204. London: Academic Press.

Thorne, A.G. 1980. The longest link: human evolution in southeast Asia and the settlement of Australia. In J. Fox, R. Garnaut, P. McCawley, and J. Mackie (eds), Indonesia: Australian Perspectives, pp. 35-43. Canberra: The Australian National University.

Thorne A. and. R. Sim 1994. The gracile male skeleton from late Pleistocene King Island, Australia. Australian Archaeology 38:8-10.

Thorne, A.G. and S.R. Wilson. 1977. Pleistocene and recent Australians: a multivariate comparison. Journal of Human Evolution 6:393-402.

Tulsi, R.S. 1972. Vertebral column of the Australian aborigine: selected morphological and metrical features. Zeitschrift für Morphologie und Anthropologie 64:117-44.

de Villiers, H. 1968. The Skull of the South African Negro: A Biometrical and Morphological Study. Johannesburg: Witwatersrand University Press.

Webb, S.G. 1989. The Willandra Lakes Hominids. Canberra: The Australian National University.

Webb, S.G. 1995. Palaeopathology of Aboriginal Australians: Health and Disease Across a Hunter-Gatherer Continent. Cambridge: Cambridge University Press.

Weidenreich, F. 1945. The Keilor skull: a Wadjak type from southeast Australia. American Journal of Physical Anthropology.

Willis, C.J. 1998. 'The Dome of Thought, the Palace of the Soul': Interpreting the Craniological Morphology of Ancient and Near-contemporary Australian Aborigines. Unpublished PhD thesis, Department of Archaeology and Anthropology, The Australian National University, Canberra. 